\title{
OPTIMAL DESIGN AND DAMAGE TOLERANCE VERIFICATION OF AN ISOGRID STRUCTURE FOR HELICOPTER APPLICATION
}

\author{
Donald J. Baker \\ Vehicle Technology Directorate - ARL \\ NASA Langley Research Center \\ Hampton, VA 23681 \\ Jack Fudge $^{+}$ \\ Hexcel Corporate Research and Technology \\ 11711 Dublin Blvd \\ Dublin, CA 94583
}

\author{
Damodar R. Ambur ** \\ NASA Langley Research Center \\ Hampton, VA 23681
}

Christos Kassapoglou
Sikorsky Aircraft
6900 Main St.
Stratford, CT 06615

A composite isogrid panel design for application to a rotorcraft fuselage is presented. An optimum panel design for the lower fuselage of the rotorcraft that is subjected to combined in-plane compression and shear loads was generated using a design tool that utilizes a smeared-stiffener theory in conjunction with a genetic algorithm. A design feature was introduced along the edges of the panel that facilitates introduction of loads into the isogrid panel without producing undesirable local bending gradients. A low-cost manufacturing method for the isogrid panel that incorporates these design details is also presented. Axial compression tests were conducted on the undamaged and low-speed impact damaged panels to demonstrate the damage tolerance of this isogrid panel. A combined loading test fixture was designed and utilized that allowed simultaneous application of compression and shear loads to the test specimen. Results from finite element analyses are presented for the isogrid panel designs and these results are compared with experimental results. This study illustrates the isogrid concept to be a viable candidate for application to the helicopter lower fuselage structure.

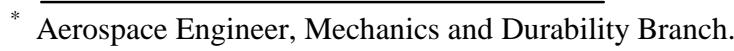

** Head, Mechanics and Durability Branch. Associate Fellow, AIAA

${ }^{+}$U. S. Technical Lead for HexMC.

${ }^{++}$Consultant. Senior AIAA member.
}

This material is a work of the U. S. Government and is not subject to copyright protection in the United States.

\begin{abstract}
$\underline{\text { Introduction }}$
As the use of composites in helicopter fuselage structures increases, the type of structural application, the combination and intensity of applied loads, and the manufacturing process become important factors that will dictate the choice of a design concept. This is of particular importance for primary aircraft structures where issues such as damage tolerance, fatigue performance, and crash absorption capability are coupled with the requirement of low cost. Traditionally, rotorcraft composite fuselages made use of sandwich or skin-stiffened structures. For low (0 $100 \mathrm{lbs} / \mathrm{in}$.) to moderate $(100-300 \mathrm{lbs} / \mathrm{in}$.) applied load levels, the sandwich structure was shown to be more efficient. For high load levels (300-800 lbs/in.), the skin-stiffened design, when allowed to postbuckle, results in light weight structures. At the intermediate range of applied loads, either sandwich or stiffened skin structure can be shown to be more weight efficient depending on the application.
\end{abstract}

Grid-stiffened structure is another concept that can be used in the intermediate range of applied load levels, which has the potential of being very efficient and damage tolerant. Grid-stiffened metal structures have been used in applications for a long time (e.g., WW II Vickers-Wellington) but the transition to composite structures has been slow for the following reasons: (a) High fabrication cost, (b) Concerns for outof-plane failure modes at the skin-stiffener interface, and (c) Lack of effective structural features for load introduction.

The use of a hand layup process for fabrication of the stiffeners makes the cost of a composite gridstiffened panel prohibitive. In addition, since the load transfer between the grids and skin is through a thin resin layer, there is potential for delamination at that 
interface at relatively low loads and, since there are no means to arrest it, its propagation usually leads to catastrophic failure of the structure. Finally, the presence of a multitude of stiffeners at the edge of a grid-stiffened panel would require special provisions such as shear and tension clips to transfer load from the grid to adjacent panels which would increase the assembly cost significantly. However, recent progress in automated fabrication methods such as fiber placement, the formulation of toughened resins, and the development of new design concepts and analytical tools have the potential to overcome these issues. Present technology suggests that it is now possible to develop composite grid-stiffened structures that are weight and cost competitive with other concepts and also with increased damage tolerance and simple structural details to efficiently transfer load to adjacent structures.

In this work, the lower fuselage structure of a large transport helicopter fuselage was chosen as a primary structural application for the grid-stiffened concept. This structure experiences intermediate load levels and would be ideal for evaluating sandwich, skin-stiffened and grid-stiffened design concepts. Also an isogrid (instead of an orthogrid) concept was chosen in this study for the grid-stiffened structure since isogrid is more suited for combined loading capability due to its diagonal stiffeners. Typical dimensions for the lower fuselage panels are 20 -inches by 56-inches. A schematic of the grid-stiffened lower fuselage structural concept is shown in Figure 1. The gridstiffened skin panel that would form the basis for the structural evaluation of the concept is also shown in Figure 1. Typical ultimate loads (corresponding to different load cases) for the panel are shown in Table 1. Only compression load cases are shown as being more critical.

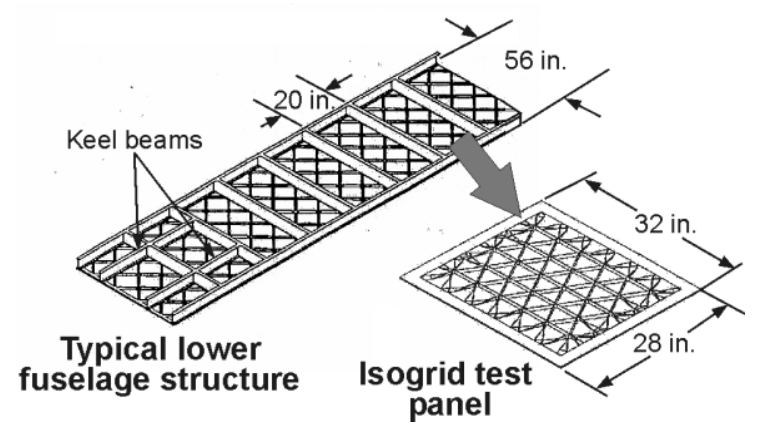

Figure 1. Isogrid application for helicopter lower fuselage structure.
Table 1. Typical load cases for the helicopter lower fuselage structure

\begin{tabular}{cc}
\hline \hline $\mathrm{N}_{\mathrm{y}}^{\mathrm{a}}$, & $\mathrm{N}_{\mathrm{xy}}$, \\
$\mathrm{lbs} / \mathrm{in}$ & $\mathrm{lbs} / \mathrm{in}$. \\
\hline-396 & 130 \\
-326 & 178 \\
-271 & 139 \\
-174 & 154 \\
-173 & 221 \\
\hline \hline along the 20-inch dimension of structure
\end{tabular}

Preliminary design of a 20 -inch by 56 -inch panel using analysis in reference [1] (modified for composites) and a gradient-based optimization (reference [2]) under the loading conditions in Table 1 indicated that a grid-stiffened panel would weigh a few percent more than a two-ply per facesheet sandwich panel with 0.5 -inch-thick core $\left(3 \mathrm{lb} / \mathrm{ft}^{3}\right.$ density). As a result, it was decided to pursue optimization of the gridstiffened design further, using genetic algorithms. In addition, an improved fabrication method and a panel edge design (stiffener runout) concept were investigated. Two panel designs were considered in this study. The first panel design used analysis in references 1 and 2 and was for compression loading condition only. The second panel design was optimized using an improved smeared stiffener analysis (reference 3) for a combined compression and shear loading condition. A special fixture was designed for testing of panels in combined compression and shear loading. This design modifies an existing edge loaded shear test fixture to allow for the application of compression loads.

Three panels were fabricated and tested for structural design verification. The first two were for a compression loading condition and the second was for a combined loading condition. Tests were performed on individual elements cut out of a full-scale compression panel to interrogate strength of the stiffener, load transfer from the panel edge with tapered stiffeners to the full grid height portion of the panel, the stiffener intersection, and the compression buckling response and strength of the panels with and without impact damage. The third full size panel was tested in combined compression and shear loading. The details of the design for optimum geometry, fabrication method, finite element analysis, test results, and correlation of analysis results with test data will be presented in this paper. 


\section{Structural Sizing}

\section{Design approach}

The panel design was conducted using an analysis method developed in Reference [3]. The method utilizes an improved smeared stiffener theory and includes local buckling of the stiffeners and the skin in the design (References [4] and [5]). The design process begins with a random selection of the specified number of designs, which comprise the initial population (i.e., first generation) for the genetic algorithm. The fixed design parameters such as material properties, panel length and width, boundary conditions of the panel, and the design loads are input into the analysis processor. The buckling analyses are performed, which provide the critical eigenvalues for the global buckling response of the grid-stiffened panel and the local buckling response of the skin and stiffener segments. The weight per unit area of the panel is also computed. This procedure is also repeated for each design configuration in the population with stiffener spacing, stiffener height and stiffener thickness as design variables. The fitness processor then evaluates the fitness of each design using Equation 8 in Reference [5] and assigns a rank based on the fitness expression or the objective function. The current population of design configurations is then assessed by the genetic operators to create a new population of design configurations for the subsequent generations, which are combined with the most desirable characteristics of the previous generations. This process is repeated until design convergence is obtained. This procedure was used to design the helicopter lower fuselage structure by approximating it as a flat panel.

\section{Panel design}

Some manufacturing constraints were also imposed on the design parameters. The skin was required to have stiffnesses that are comparable to a quasi-isotropic laminate and the stiffener thickness was limited to not exceed 0.25 -inch due to manufacturing constraints. The design loads used are shown in Table 1.

The geometric details of two manufacturing process demonstration panels, one of which was used for conducting the element tests and the second for testing under axial compression, are presented in Table 2. This panel was designed for a $400 \mathrm{lbs} / \mathrm{in}$. compression loading condition using the method outlined in reference 1 . This panel is referred to as the "compression panel" in the paper. The results from the panel test were used to verify the analytical buckling load predictions from the method in reference 3 and the finite element analysis. Element test results were used to study the load carrying capability of different structural details including the panel edge region. The strength constraints were also identified from the compression panel tests that were used for the design of a third panel for combined compression and shear loading.

Following the process described above, the design of a 20 -inch by 56 -inch isogrid panel that meets the combined loading conditions for the lower fuselage panel was completed using the design tool described in reference 3. The design details of this panel, referred to as the "combined loading panel," are presented in Figure 2. The panel buckling load interaction curve for the axial compression and shear loads for this panel design is shown in Figure 3, which illustrates that the panel design requirements from Table 1 (shown as open symbols) are within the bounds of the actual design envelope.

Table 2. Geometry and analytical loading capability information for compression loaded isogrid

\begin{tabular}{lc}
\hline \multicolumn{1}{c}{ Variable } & Value \\
\hline Panel X-dimension & $20 \mathrm{in}$. \\
Panel Y-dimension & $56 \mathrm{in.}$ \\
Stiffener thickness & $0.042 \mathrm{in}$. \\
Stiffener height & $0.66 \mathrm{in.}$ \\
(measured from skin surface) & \\
Stiffener orientation & $60^{\circ}$ \\
Number of unit cells in X-direction & 4 \\
Number of unit cells in Y-direction & 5 \\
Skin ply stacking sequence & {$[60 /-60 / 0 /-$} \\
& $60 / 60]$ \\
Skin ply thickness & $0.007 \mathrm{in}$. \\
Structural weight & $0.48 \mathrm{lbs} / \mathrm{ft}^{2}$ \\
& \\
Estimated buckling loads (lbs/in.): & \\
\cline { 1 - 2 }$\quad$ Global & -1077 \\
Skin & -108 \\
Axial stiffener & -150 \\
Diagonal stiffener & $-2,150$ \\
\hline \hline
\end{tabular}

\section{Weight comparisons}

The loading condition of $400 \mathrm{lbs} / \mathrm{in}$. compression and $240 \mathrm{lbs} / \mathrm{in}$. shear, was used to design the same 56 in. $x 20$ in. panel as a sandwich or a stiffened skin design. For the sandwich, the requirement that the core thickness be in multiples of 0.25 -in. and the core density no less than $3 \mathrm{lb} / \mathrm{ft}^{3}$ was 


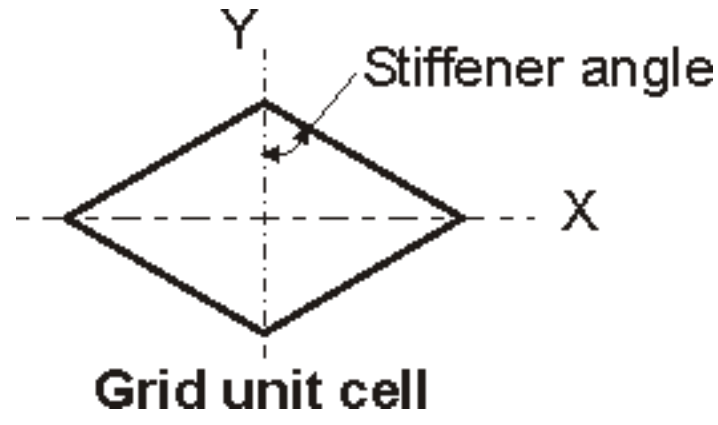

$\begin{array}{ll}\text { Panel X-dimension: } & 20 \mathrm{in} . \\ \text { Panel Y-dimension: } & 56 \mathrm{in.} \\ \text { Thickness of stiffener: } & 0.114 \mathrm{in} . \\ \begin{array}{l}\text { Height of stiffener: } \\ \quad \text { (measured from skin) }\end{array} & 0.5375 \mathrm{in} . \\ \begin{array}{l}\text { Stiffener orientation: } \\ \text { No. of unit cells in the }\end{array} & 60^{\circ} \text { to the Y-axis } \\ \quad \text { X-direction: } & 3 \\ \begin{array}{l}\text { No. of unit cells in the } \\ \text { Y-direction: }\end{array} & 5 \\ \begin{array}{l}\text { Skin layup: } \\ \text { Skin ply thickness: }\end{array} & {[60 /-60 / 0 /-60 / 60]} \\ \text { Structural weight: } & 0.006 \mathrm{in} . \\ & 0.512 \mathrm{lbs} / \mathrm{sq} . \mathrm{ft} .\end{array}$

Figure 2. Design information for isogrid subjected to combined compression and shear.

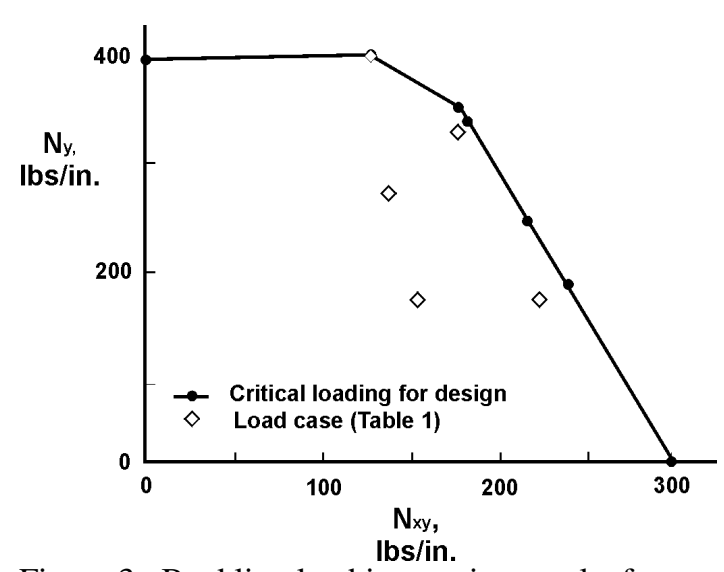

Figure 3. Buckling load interaction results for isogrid panel design.

imposed (the latter to maintain strength and stiffness properties at elevated temperature wet conditions). The two best configurations were found to be the designs with two, $\left[45^{\mathrm{f}} / 0^{\mathrm{f}}\right]$ or three, $\left[45^{\mathrm{f}} / 0^{\mathrm{f}} / 45^{\mathrm{f}}\right]$, plies per facesheet. Where the superscript " $\mathrm{f}$ " denotes a ply of plain weave carbon-epoxy fabric. In the case of two plies per facesheet, it is necessary to add a protective coating (adhesive layer) on either side to protect the facesheets and core from moisture ingression. In the weight calculations, only the weight of the facesheetes, adhesive (including protective coating against moisture), and core were included. There is additional weight due to core splices, local core densification for attachments, and pad-ups or doubler reinforcements. This ancillary weight can be as much as $30 \%$ of the total weight and was not included here. The corresponding extra weight for an isogrid design is usually less and is in the form of reinforcement around the panel and bushings used at nodes of intersecting stiffeners for attachment of other members such as frames.

For the skin-stiffened design, the driving requirement was that the buckling load should be close to limit load, i.e., the post-buckling factor for the panel should not be significantly higher than 1.5 (definitely less than 2). This is because in a helicopter application, the high vibration environment and high number of high frequency cycles may lead to fatigue issues if postbuckled structure is used with high post-buckling factors. If the skin buckles for a high number of cycles, it may separate from the stiffeners or it may develop delaminations. As a result, the stiffener spacing and relative axial stiffness of skin and stiffeners should be such that the axial load in the skin is as low as possible, and such that buckling of the skin between stiffeners occurs at or near the limit load. It was determined that a skin layup of $\left[45^{\mathrm{f}} / 0_{2}^{\mathrm{f}} / 45^{\mathrm{f}}\right]$ and a stiffener layup of $\left[0^{\mathrm{f}} / 0_{4} / 0^{\mathrm{f}}\right]$ with stiffener spacing equal to 4 inches (for a total of 14 stiffeners across the 56 in. width of the panel) and a stiffener area of $0.19 \mathrm{in}^{2}$ would give the required performance with no skin buckling failure below $80 \%$ of limit, no stiffener buckling or crippling below ultimate load and no skin failure below ultimate load.

The weights of the competing designs with sandwich or skin-stiffened construction are shown in Table 3. Comparing the weight of the isogrid structure (Figure 2) with the weights shown in Table 3 it is seen that the isogrid structure is 3 percent heavier than the 2 ply facesheet sandwich structure and 26 percent lighter than the skin-stiffened structure. However, if the ancillary weight is also considered, the isogrid is expected to have a considerable advantage over the sandwich design.

\section{$\underline{\text { Test Panel Fabrication }}$}

For the fabrication method, a specialized fiber placement approach was selected and a first generation fiber placement head was developed and used. First, the stiffeners were fiber placed into an elastomeric tool, with grooves delineating the grid pattern, using single $12 \mathrm{~K}$ tows of carbon-epoxy material. Stiffener intersection points or nodes, where three stiffeners met, 
Table 3. Designs competing with the isogrid design

\begin{tabular}{|c|c|c|c|}
\hline & $\begin{array}{l}\text { Sandwich with } 2 \text { plies } \\
\text { per facesheet }\end{array}$ & $\begin{array}{c}\text { Sandwich with } 3 \text { plies } \\
\text { per facesheet }\end{array}$ & Stiffened panel \\
\hline Facesheet layup $^{a}$ & {$\left[45^{\mathrm{f}} / 0^{\mathrm{f}}\right]$} & {$\left[45^{\mathrm{f}} / 0^{\mathrm{f}} / 45^{\mathrm{f}}\right]$} & \\
\hline Core & $\begin{array}{c}0.5 \text {-in. thick, } 3 \mathrm{lb} / \mathrm{ft}^{3} \\
\text { HFT core. }\end{array}$ & $\begin{array}{c}0.5 \text {-in. thick, } 3 \mathrm{lb} / \mathrm{ft}^{3} \mathrm{HFT} \\
\text { core. }\end{array}$ & \\
\hline Adhesive & $4-0.03 \mathrm{lb} . / \mathrm{ft}^{2}$ layers ${ }^{\mathrm{b} c}$ & $4-0.03 \mathrm{lb} / \mathrm{ft}^{2}$ layers ${ }^{\mathrm{b}}$ & \\
\hline Skin layup & & & {$\left[45^{\mathrm{f}} / 0_{2}^{\mathrm{f}} / 45^{\mathrm{f}}\right]$} \\
\hline Stiffener layup & & & {$\left[0^{\mathrm{f}} / 0_{4} / 0^{\mathrm{f}}\right]$} \\
\hline Stiffener area & & & $0.1935-$ in $^{2}$ \\
\hline Stiffener spacing & & & 4.0-inches \\
\hline Design requirements & $\begin{array}{l}\text { No buckling below } \\
\text { ultimate load. } \\
\text { No wrinkling dimpling }\end{array}$ & $\begin{array}{l}\text { No buckling below } \\
\text { ultimate load. } \\
\text { No wrinkling, dimpling }\end{array}$ & $\begin{array}{c}\text { No overall, bay, or } \\
\text { stiffener buckling below } \\
80 \% \text { of limit. }\end{array}$ \\
\hline & or open hole failure. & or open hole failure. & $\begin{array}{l}\text { No stiffener crippling or } \\
\text { skin failure below } \\
\text { ultimate load. }\end{array}$ \\
\hline Weight $\left(\mathrm{lb} / \mathrm{ft}^{2}\right)$ & 0.49 & 0.56 & 0.65 \\
\hline
\end{tabular}

\footnotetext{
a " $\mathrm{f}$ " indicates a ply of plain weave carbon-epoxy fabric.

${ }^{\mathrm{b}}$ Adhesive layer between facesheet and core (2 layers total).

${ }^{c}$ An additional layer on the outside to protect against moisture ingression (2 layers total).
}

were designed with an offset so that only two stiffeners intersect at a time creating a small triangle at each intersection point. This feature results in the thickness stack-up to reduce from three to two times the stiffener height. In addition, roller pressure at intersection points was increased to maintain a constant stiffener height throughout the grid (with an associated local spreading of fibers and increase in fiber volume). A controlled reference height on the automated head provided low pressure on the single stiffeners and high pressure at the intersection. The edge of the panel was fabricated by first laying 6 plies of fabric in a tool recess to form the panel edge. At the edges of the panel, individual tows were steered in a fan pattern that increased the grid footprint and tapered down the height of the grid. In effect, each stiffener was gradually rotated from a vertical to a horizontal position instead of twisting the stiffener, individual fibers were steered into the desired position. A sketch of the grid intersection and grid termination at the panel edges is given in Figure 4. The skin was subsequently laid on top of the elastomeric tool containing the stiffener material. The entire assembly was bagged and cured. During cure, the elastomeric tool expanded under the autoclave pressure thus providing side pressure to consolidate the stiffener grid.

A low cost single fiber head, in contrast to the expensive traditional multi-tow fiber placement head, was used to lay down the grid structure. Automation scale up can easily be achieved by associating one head with each stiffener. The fiber placement heads associated with one of the primary directions (2 orthogrid; 3 - isogrid) can be linked together to create a single pass in the $0 / 60 /$ or -60 direction and to coordinate the steering that creates the edge transition.

All three panels were fabricated to have dimensions of 28 -inches by 32 -inches. The first two panels were hand laid (including the grids) due to unavailability of the fiber placement machine. The third panel was fiber placed using an automated process.

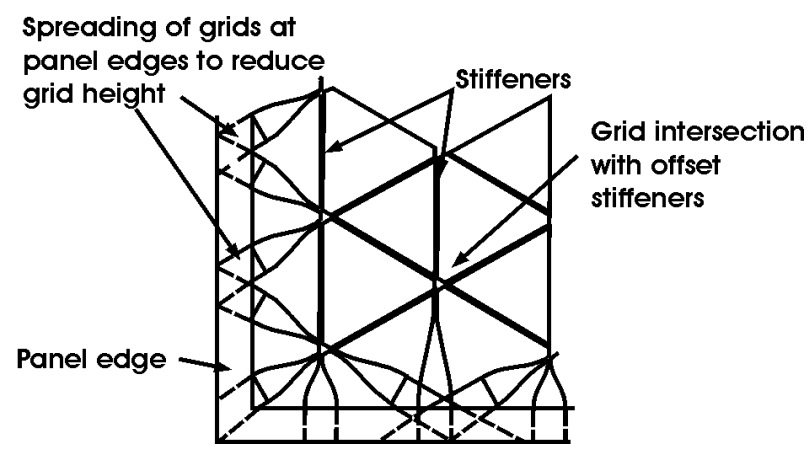

Figure 4. Isogrid panel details. 


\section{$\underline{\text { Panel Analysis }}$}

\section{Analysis tools and solution procedure}

The isogrid panels considered in this study were analyzed using STAGS (STructural Analysis of General Shells) nonlinear shell finite element analysis computer code (reference [6]). STAGS is a computer code for the static and dynamic analysis of general shells, and includes the effects of geometric and material nonlinearities in the analysis. The code uses both the modified and full Newton methods for its nonlinear solution algorithms, and accounts for large rotation in a shell by using a co-rotational algorithm at the element level. The Riks pseudo arc-length pathfollowing method (reference [7]) is used to continue a solution past the limit points of a nonlinear response. With this strategy, the incrementally applied loading parameter is replaced by an arc-length along the solution path, which is then used as an independent loading parameter. The arc length increment is automatically adjusted by the program as a function of the solution behavior. The code also contains a solution branch switching algorithm that offers the user the opportunity to jump from one solution path to another in the vicinity of a bifurcation point. The transient analysis option in STAGS uses proportional structural damping and an implicit numerical time-integration method developed by Park (reference [8]).

\section{Compression panel analysis}

The compression panel was analyzed using the method outlined in reference 3 to determine local and global buckling loads. The analytical buckling results are: (a) Skin buckling $=108$ lbs/in., (b) Global buckling $=1,077 \mathrm{lbs} / \mathrm{in}$. , (c) Axial stiffener $=150$ lbs/in., (d) Diagonal stiffener $=2,150 \mathrm{lbs} / \mathrm{in}$. The detailed panel response was analyzed using the STAGS code

A finite element model of the isogrid panel tested in compression is shown in Figure 5. The model contains 3,987 nodes, 4,091 quadrilateral elements and 113 triangular elements. The quadrilateral elements and triangular elements are standard elements from the STAGS element library. A geometrically perfect panel was analyzed with this model. Nominal panel geometry, lamina thickness and material properties for AS-4/3501-6 carbon-epoxy material system were used in the finite element analysis. The boundary condition models the end-potting material as a rigid material. Panel sides were modeled with a simply supported condition. The compression buckling load was predicted to be $715 \mathrm{lb} / \mathrm{in}$. which is $30 \%$ less than that estimated using the smeared stiffener theory (ref Table 2). A linear analysis predicted an end shortening of 0.047 inches, which translates to a panel axial stiffness of $425,812 \mathrm{lbs} / \mathrm{in}$.

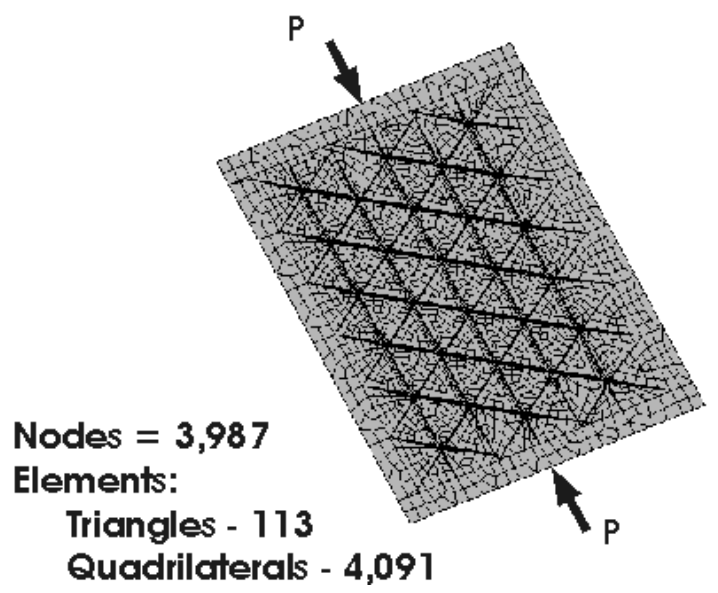

Figure 5. Finite element model of the compression loaded panel.

A linear eigenvalue analysis predicted the initial buckling in the skin at $101.2 \mathrm{lbs} / \mathrm{in}$. which compares well with the analytical prediction of 108 $\mathrm{lb} / \mathrm{in}$. The finite element analysis predicted initial local buckling mode shape and location is shown in Figure 6.

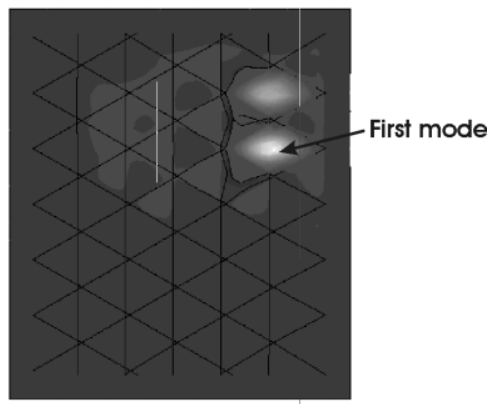

Figure 6. Location of predicted first buckling mode at $101 \mathrm{lbs} / \mathrm{in}$. in compression loaded panel.

A nonlinear analysis was also performed on the compression panel. The analysis results did not converge beyond approximately $600 \mathrm{lbs} / \mathrm{in}$. since multiple skin elements and axial stiffener elements were in a postbuckled state. The analysis was terminated at this point. An initial geometric imperfection was not used to start this nonlinear 
analysis. The predicted end shortening as a nonlinear function of load as shown in Figure 7. These results suggest nonlinear response for this panel starts below $400 \mathrm{lbs} / \mathrm{in}$., where extensive local buckling of skin and stiffener elements occurs. The predicted end shortening from the nonlinear analysis is 0.046 inches at 588 lbs/in. The calculated panel stiffness at this point is $359,564 \mathrm{lbs} / \mathrm{in}$. which is 16 percent lower than the linear stiffness value. Out-of-plane defection predictions for the compression panel at load conditions above and below $400 \mathrm{lbs} / \mathrm{in}$. are shown in Figure 8. As seen in the Figure, the out-of-plane deflection increases as the load increases and the number of triangular skin

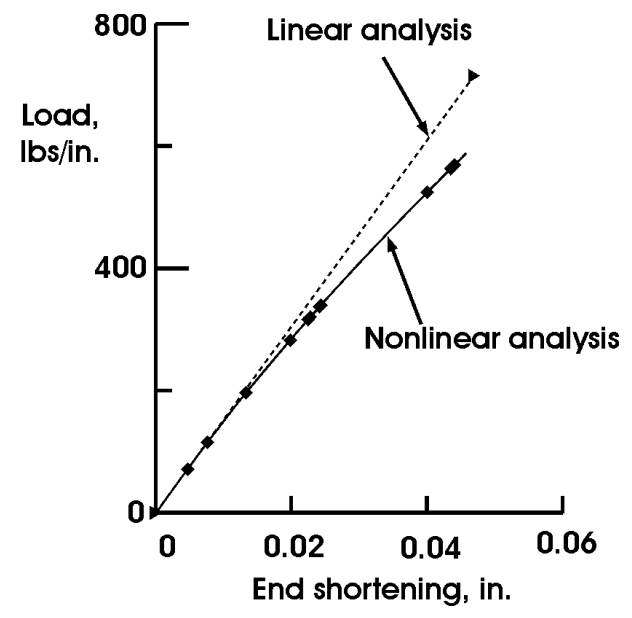

Figure 7. Predicted panel end-shortening response for the compression panel.
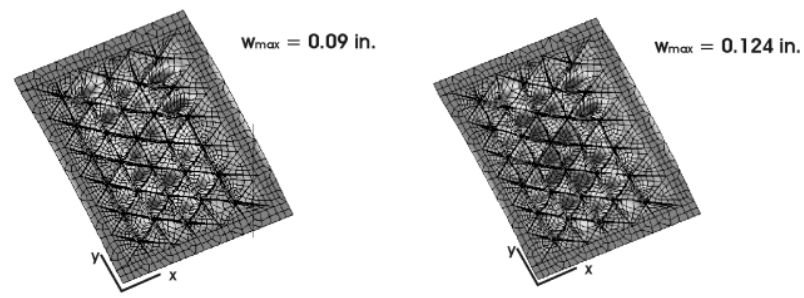

a. $\mathrm{N}_{\mathrm{y}}=314 \mathrm{lbs} / \mathrm{in}$.
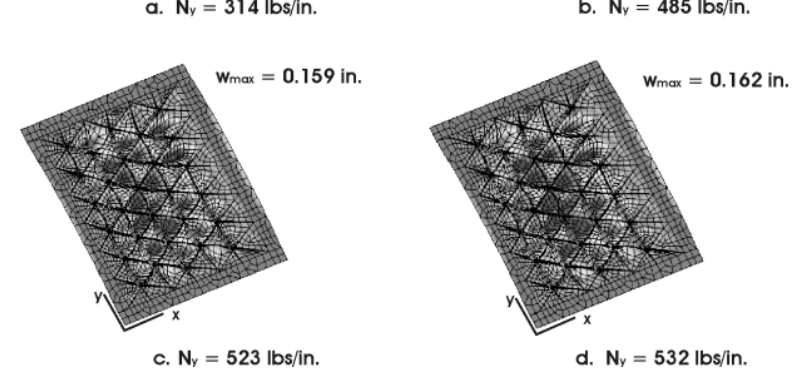

Figure 8. Predicted out-of-plane displacements at increasing compression loads. elements that experience out-of-plane deflection increases. More analysis results are presented later in the section on experimental results.

\section{Combined load panel analysis}

A finite element model of the isogrid panel in a combined compression and shear loading fixture is shown in Figure 9. The model contains 16,533 nodes, 16,476 quadrilateral elements and 2 triangular elements. The test specimen and the test fixture are modeled to insure that proper kinematics are incorporated in the analysis. The quadrilateral elements and triangular elements are standard elements from the STAGS code element library. A geometrically perfect panel model

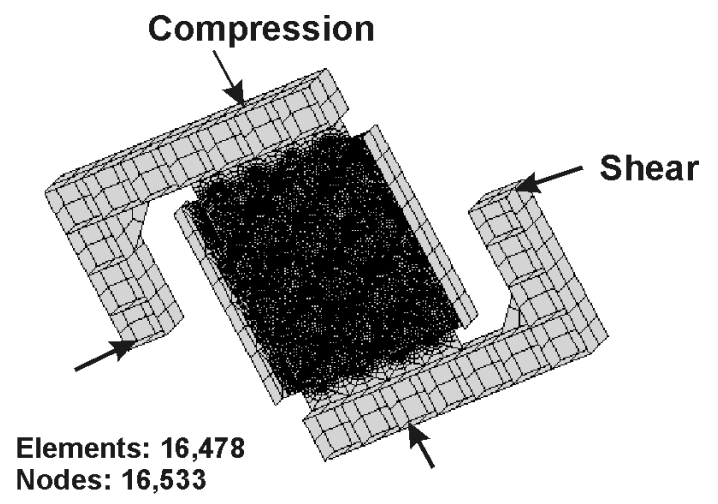

Figure 9. Finite element model of combined loading panel and test fixture.

was used in the analysis. Nominal panel geometry, lamina thickness and material properties for AS4/3501-6 carbon-epoxy material system were used in the finite element model. The panel test was planned with three different loading conditions: Condition A 400 lbs/in. in compression with no shear load, Condition $B$ - $240 \mathrm{lbs} / \mathrm{in}$. in shear with no compression load, and Condition $C$ - Combined load of $400 \mathrm{lbs} / \mathrm{in}$. in compression and $240 \mathrm{lbs} / \mathrm{in}$. in shear. The same ratio of shear load to compression load was maintained throughout the loading. The results from linear analyses for these loading conditions will be presented in later sections of the paper together with the test data.

A linear eigenvalue analysis was also performed for each loading condition. The predicted initial buckling load results for each loading condition are as follows: Condition $A-123 \mathrm{lbs} / \mathrm{in}$. in compression, Condition $B-64$ lbs/in. in shear and Condition $C-69 \mathrm{lbs} / \mathrm{in}$. compression and $40 \mathrm{lbs} / \mathrm{in}$. shear. The analysis results for each of these loading conditions predicted buckling of the skin element identified in the corner of the panel in Figure 10. 


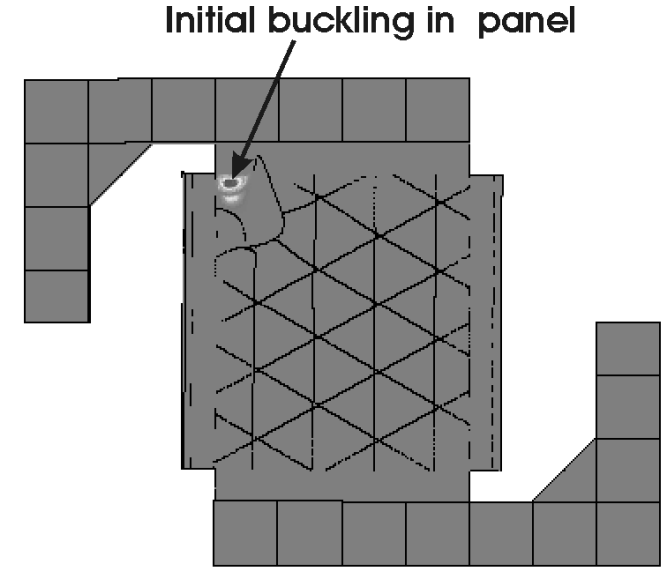

Figure 10. Predicted location of initial buckling for compression, shear, and combined compression and shear load conditions.

\section{$\underline{\text { Experimental results }}$}

All element and panel testing was performed at room temperature with the specimens in the asfabricated condition. The element tests were used to investigate the stiffener, skin/stiffener interface responses, and load introduction through the tapered stiffener height at the panel edge. The panel tests were conducted to study local buckling, global buckling, and failure responses for compression and combined compression and shear loading conditions. Data was collected with a computer controlled data acquisition system. Moiré interferometry technique was used to monitor out-ofplane displacements whenever the test specimen surface was accessible.

\section{Element tests}

Eight single and multistiffener element specimens were created from the first full-scale compression panel for axial compression and bend testing. These tests on individual elements were performed to interrogate the response of skin/stiffener, skin/stiffener-grid intersection region, the load transfer from the panel edge to the full grid height portion of the panel, and the grid intersection. Photographs of the element test specimens are shown in Figure 11.
Element specimens 1, 2, and 8, shown in Figure 11a-c, were tested in four-point bending to investigate the bending response and the integrity of the stiffener-skin interface for bending of the skin-stiffener combination either toward or away from the skin surface. Specimen 1 is 18.5 -inches-long and has a single stiffener that includes 3 nodes (point where the stiffeners intersect). This specimen was tested with skin side facing down while supported at mid-span of the outer bays and was loaded at the outer nodes. Results from strain gages on the stiffener are shown in Figure 12. The results indicate that the stiffener rolled and failed by cracking at the base near the skin and near the top of the stiffener at the strain gage location. Load at failure was $160 \mathrm{lbs}$. Element specimen 2 is 13.8inches-long with a single stiffener and includes 3 nodes. Specimen 2 was tested skin side facing up while supported at the outer nodes and was loaded at the center of adjacent bays. Results, shown in Figure 13, from the strain gages on the skin indicate that skin bending started at approximately $50 \mathrm{lbs}$. of load and the specimen continued to carry load until failure at 120 lbs. Specimen 8 is 3 -stiffener bay wide and extends over 5 nodes ( 23 inches). The specimen was tested in bending with its skin side facing down. Results shown in Figure 14 indicate that the skin identified by the diamond symbol started bending as soon as the loading was applied (Figure 14a) and continued to bend until failure occurred near the skin-stiffener interface at 330 lbs. The center stiffener also started to bend at a low

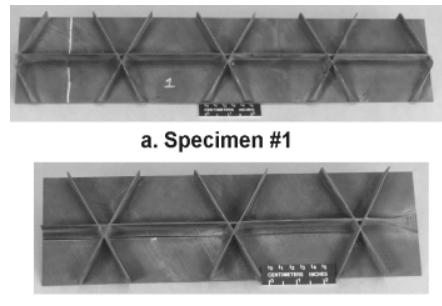

b. Specimen \#2.

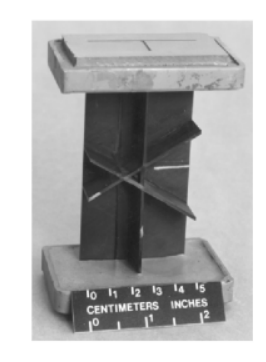

d. Specimen \#3.

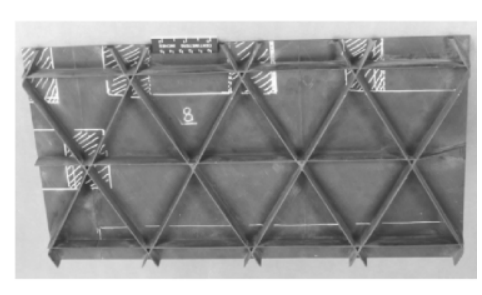

c. Specimen \#8.
Figure 11. Element test specimens. 


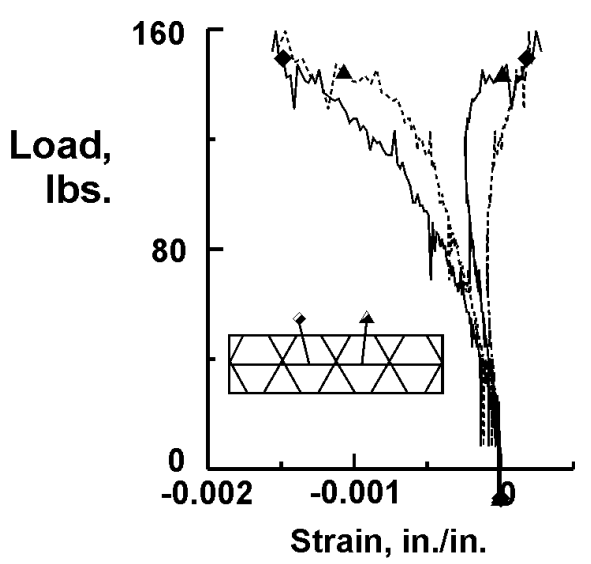

Figure 12. Strain in specimen 1 stiffeners.

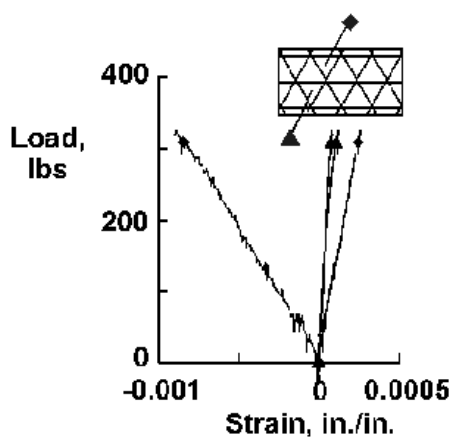

a. Strain in skin

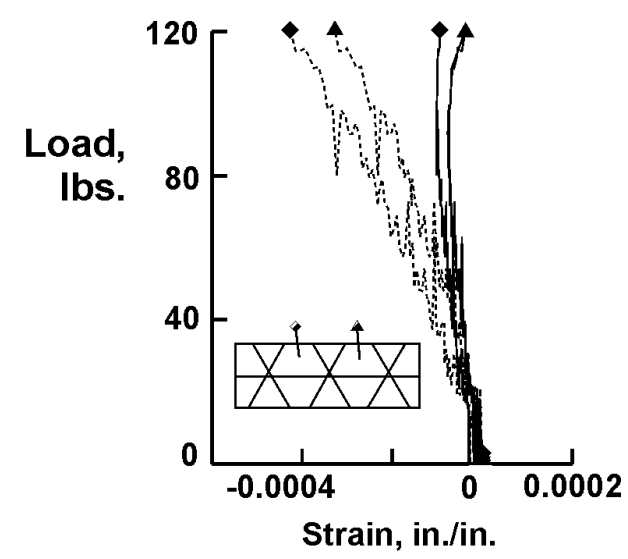

Figure 13. Strain in specimen 2 skin.

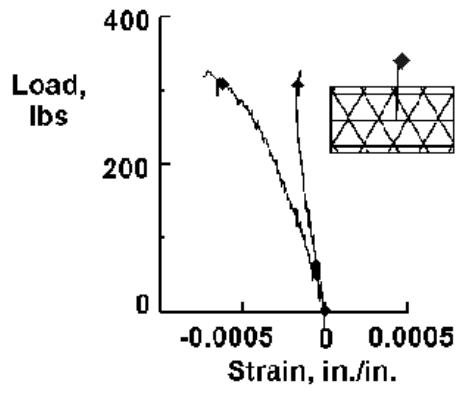

b. Strain in rib

Figure 14. Selected strain results from bending test of specimen 8 .

load value (Figure 14b), that continued until failure. In all of the cases, the specimens failed when the surface strain values in the skin and stiffener reached values of $500 \mu$ in./in. and $1200 \mu$ in./in., respectively. The failure was at or near the skin-stiffener interface.

Specimens 3 through 7 shown in Figures 11d-f were tested in compression. These tests were intended to identify the weakest link in the structure by determining the minimum load carried by a given element. Specimen 3 was tested to determine the grid intersection strength. Results for specimen 3 shown in Figure 15 indicate that the two skin elements buckled (diamond symbols) at approximately $750 \mathrm{lbs}$. and a part of the skin changed mode shape at 1,100 lbs. of load. Back-to-back gages on the vertical stiffener indicate buckling at the diamond symbol location at approximately $1000 \mathrm{lbs} / \mathrm{in}$. as shown in Figure 15b. This stiffener buckling could have contributed to change in the element buckling mode. Failure of the specimen was in the form of skin-stiffener separation at
2,660 lbs. The load introduction through the panel edge was determined by testing specimens 4 and 6 in axial compression. Specimens 4 and 6 are taken from two different stiffener termination details of the panel. Results from specimen 4 are shown in Figure 16, which indicate skin buckling on the side with diamond symbols at approximately $750 \mathrm{lbs}$. of load. A failure at the skin-stiffener interface appeared to occur at approximately 1,000 lbs. Strain data from the stiffener transition region presented in Figure 16b indicates the influence of this loss of the skin-stiffener integrity and deforms in a highly nonlinear manner resulting in the skin-stiffener separation. Maximum load for specimen failure was 1,660 lbs. or $447 \mathrm{lbs} / \mathrm{in}$. The response of specimen 6 is similar to that of specimen 4 with a maximum failure load of 1,730 lbs. or $465 \mathrm{lbs} / \mathrm{in}$. The compression response and strength of the stiffener was 


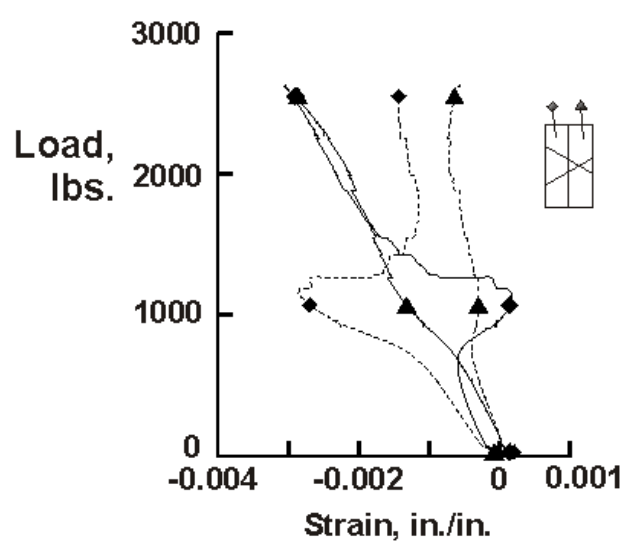

a. Strain in skin.

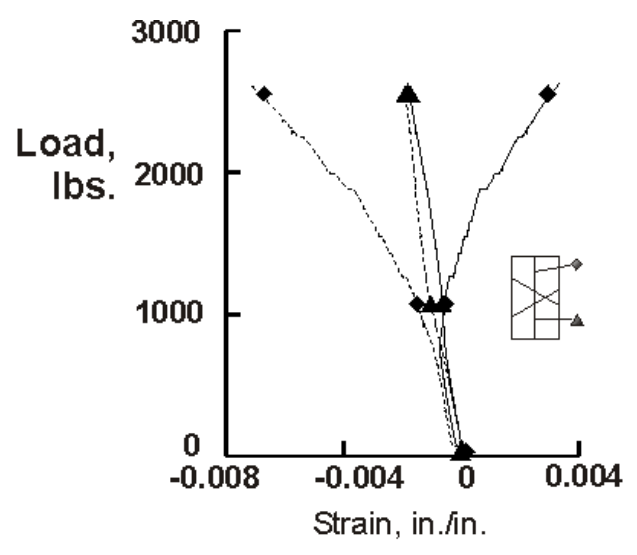

b. Strain in stiffener.

Figure 15. Compression specimen to determine grid intersection strength, specimen 3.

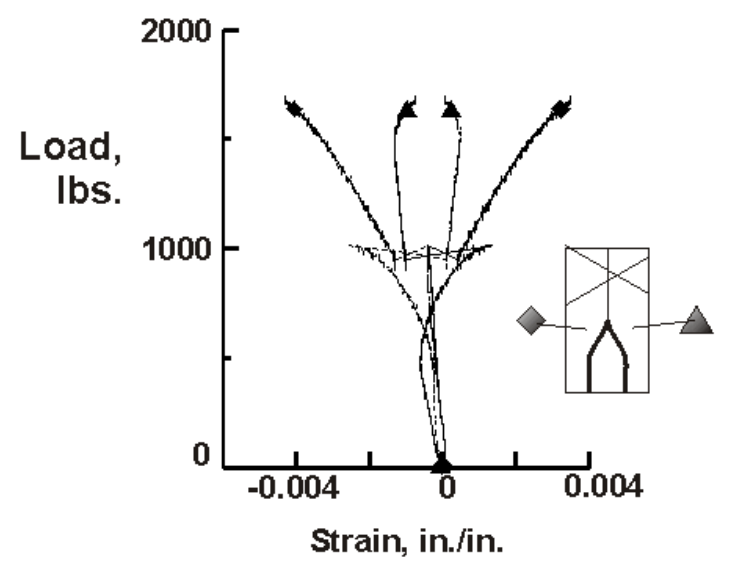

a. Strain in skin.

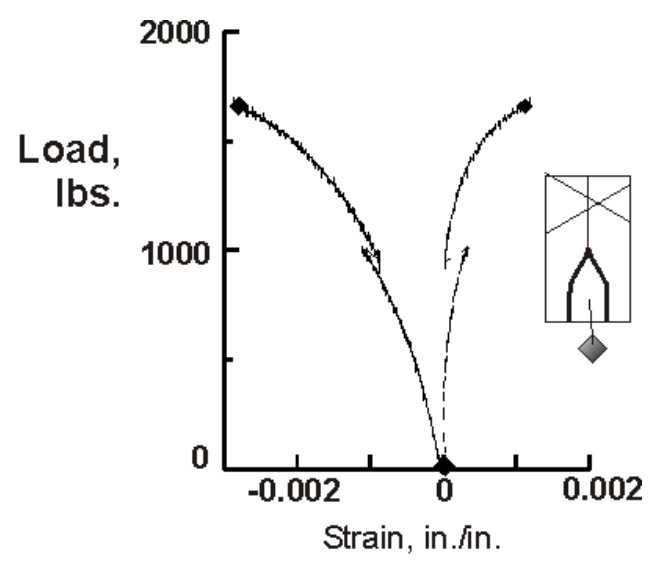

b. Strains in transition area.

Figure 16. Compression specimen to determine the edge load introduction, specimen 4.

determined by testing specimens 5 and 7, which are the same type of specimens but taken from two different locations of the panel. Results for specimen 5 are presented in Figure 17 which suggest stiffener buckling at approximately $750 \mathrm{lbs}$. of load. Specimen final failure was at $1,730 \mathrm{lbs}$. with separation of the stiffener from the skin. These element tests indicate that the panel design features offer a load capability of 1,660 lbs. or $447 \mathrm{lb} / \mathrm{in}$. and the weakest link is the load introduction region. It should be noted that these failures occur after local skin buckling which is an artifact of the specimen geometry. These element test results suggest that the design concept has efficient load transfer at the grid intersections and the panel edge designs has sufficient load carrying capability.

\section{Compression Test Specimen without and with low-speed impact damage}

The isogrid panel shown in Figure 18 was tested in compression with simply supported unloaded edges. The load versus end-shortening displacement results from the STAGS analysis and the experiment are presented in Figure 19. When the anomalies at the lower load values are accounted for, the results suggest a good agreement between the analysis and experiment. A linear least squares fit of the end-shortening curve between the loads of $150 \mathrm{lbs} / \mathrm{in}$. and $350 \mathrm{lbs} / \mathrm{in}$. provides a panel stiffness estimate of 490,297 lbs/in. and this compares well with the calculated linear stiffness of 425,812 lbs/in. Selected strain gage data for typical skin and stiffener locations are presented in Figure 20 and compared with STAGS code finite element analysis results. The strain results at gage 


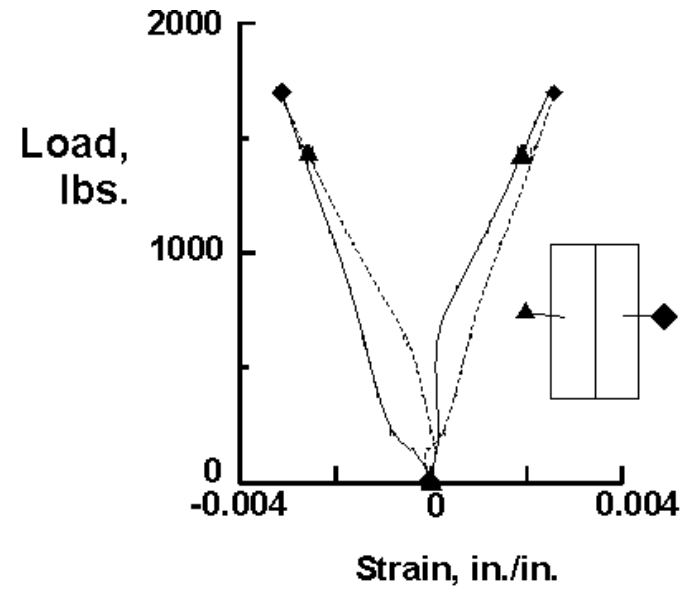

a. Strain in skin

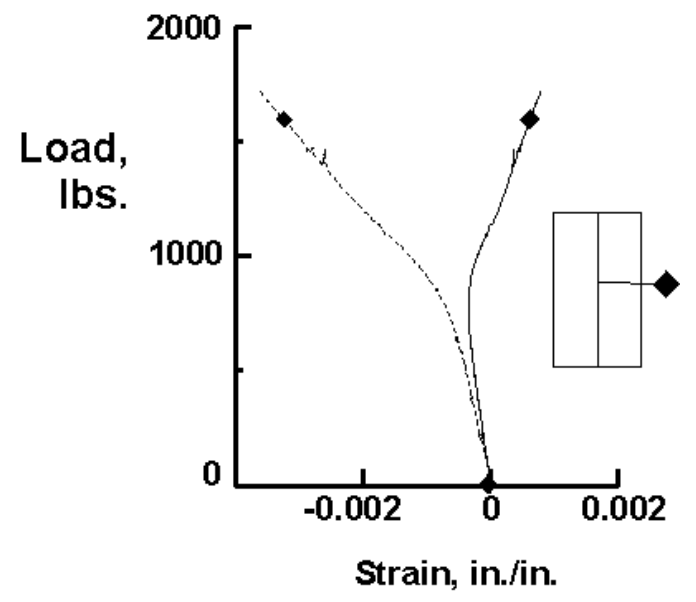

b. Strain in stiffener

Figure 17. Compression test results for specimen 5.

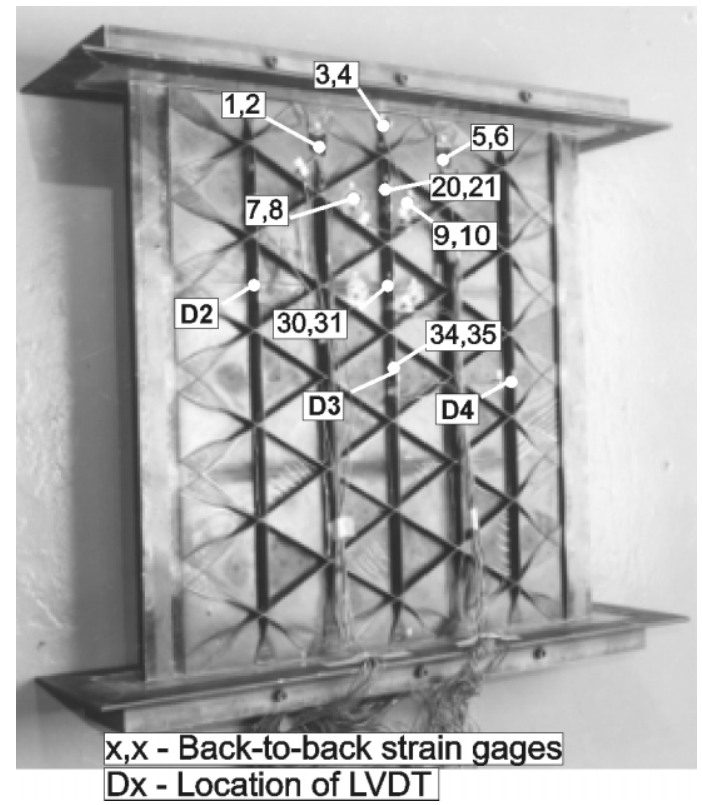

Figure 18. Compression loaded isogrid panel.

locations shown suggest stiffener and skin buckling at approximately $250 \mathrm{lbs} / \mathrm{in}$. and $275 \mathrm{lbs} / \mathrm{in}$., respectively. Although the predicted and observed buckling loads compare reasonably well, the estimated postbuckling stiffness of the skin is significantly different than the observed value. The strain results in the load introduction area are presented in Figure 20c. These results do not exhibit the jump similar to the one presented in Figure 15b for this design detail since the skin buckling mode for specimen 4 did not develop in the compression panel specimen. The panel fails before global buckling at a load of $775 \mathrm{lbs} / \mathrm{in}$., which is significantly lower than the analytical buckling load

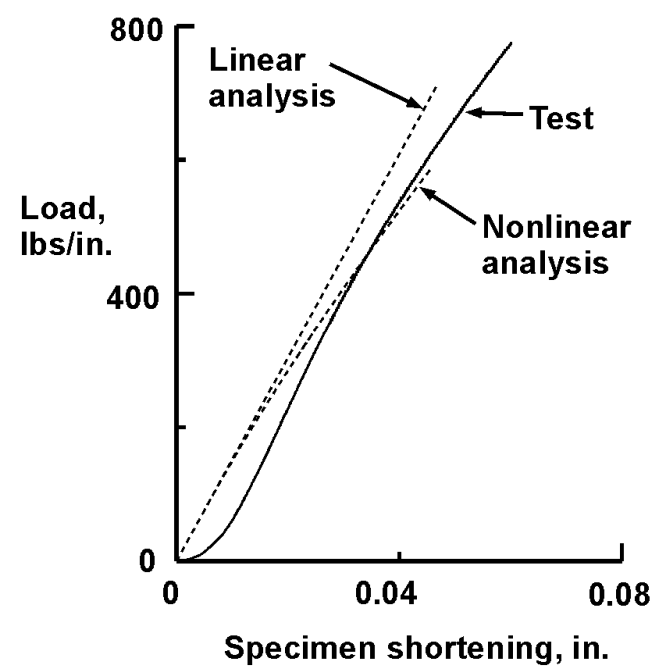

Figure 19. Predicted and measured panel end shortening.

estimate of $1,077 \mathrm{lbs} / \mathrm{in}$. (presented in Table 2). This analysis result does not account for the influence of local buckling. In the test panel skin and stiffener element buckling results in panel failure. A photograph of the failed compression panel is presented in Figure 21 with locations of failure modes clearly identified. The dominant failure modes are skin-stiffener separation in regions where significant skin buckling occurred and delamination failure along vertical regions where the panel was supported. No failures were observed in the load introduction region. 


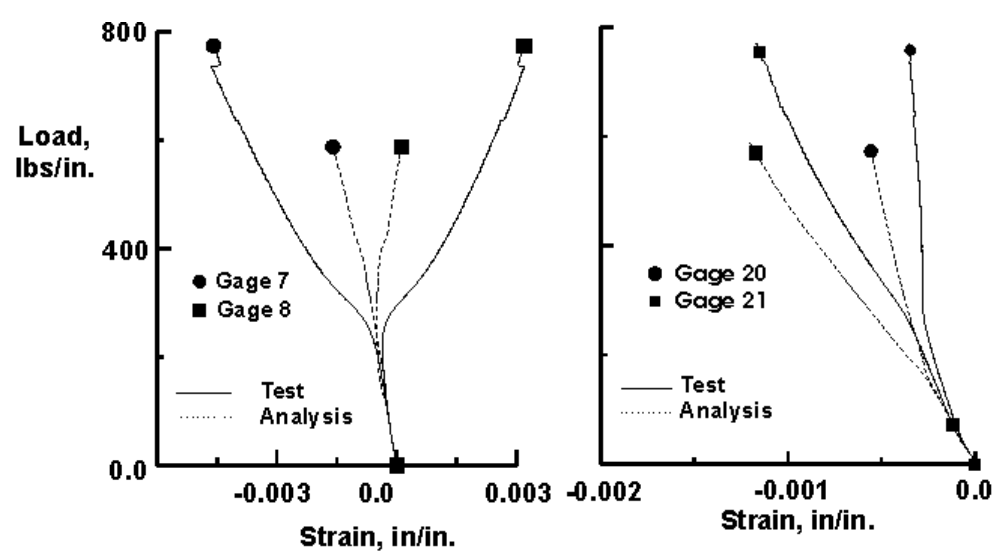

a. Strain in skin

b. Strain in stiffener

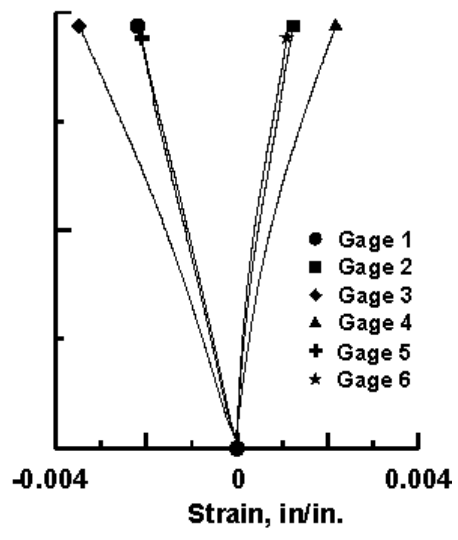

c. Strain in load intoduction area

Figure 20. Results from strain gages on compression panel.

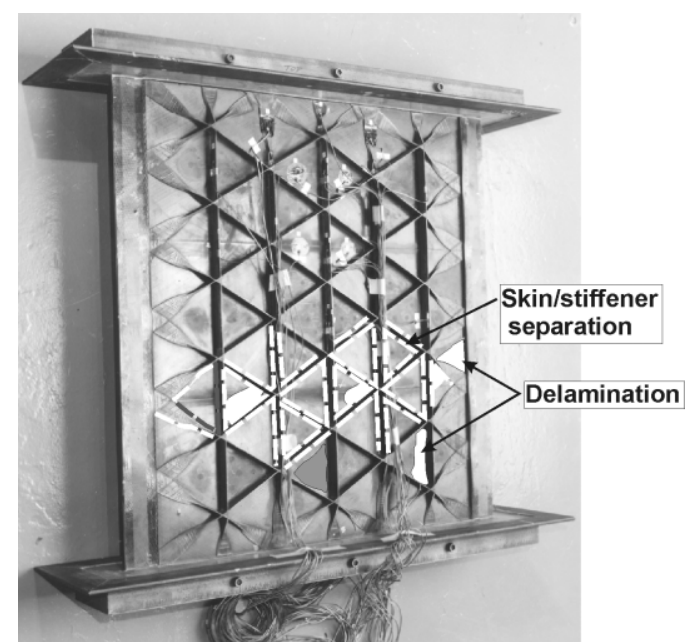

Figure 21. Failed compression loaded isogrid panel.

Nondestructive evaluation of the failed panel indicated that the damage was contained in one half of the specimen.

A smaller size panel specimen was prepared from the failed compression specimen by removing the failed half of the specimen and potting the ends as shown in Figure 22. The objective of this test was to study load redistribution around regions subjected to low-speed impact damage and the associated failure modes. This reduced length specimen was subjected to multi-site low-speed impacts in an unloaded state on the skin side at energy levels of $2.6 \mathrm{ft}-\mathrm{lbs}, 9.6 \mathrm{ft}-\mathrm{lbs}$ and $16.1 \mathrm{ft}-\mathrm{lbs}$ with an air-propelled 0.50-inch-diameter aluminum sphere at three locations identified in Figure 22. The specimen was impacted in the center of a skin bay (2.6 $\mathrm{ft}-\mathrm{lbs}$ ), at the transition from the stiffener and the skin (9.6 ft-lbs), and at a stiffener intersection location (16.1

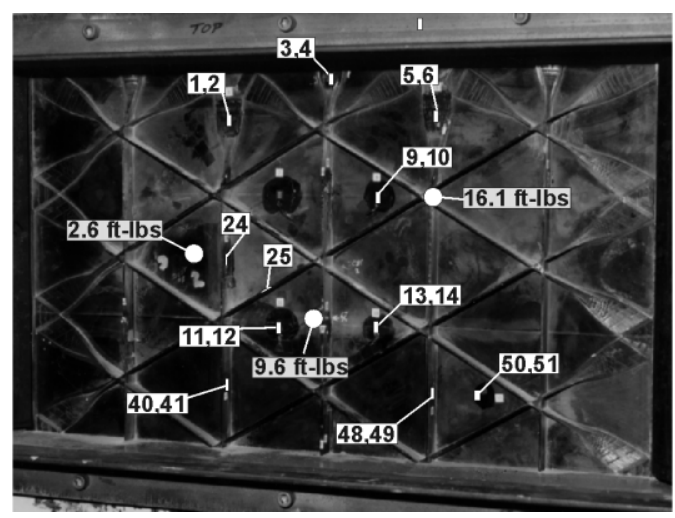

Figure 22. Impact and strain gage locations on the impacted panel.

ft-lbs). These impact energy levels were earlier determined experimentally to result in barely visible impact damage at these respective locations. The strains induced in the specimen by the impacts were recorded using a high-speed data acquisition system and the sample results are shown in Figure 23 for selected gages. The transient strain values in the skin corresponding to the $16.1 \mathrm{ft}-1 \mathrm{~b}$ impact energy attain values in excess of 3,000 $\mu$ in./in. as shown in Figure 23a whereas the strain values in the longitudinal and diagonal stiffeners do not exceed strain values of $200 \mu$ in./in. (Figure 23b). Also, unlike the airgun impact response for edge-supported, unstiffened skin panels which does not last beyond $30 \mu$ sec., the stress wave due to impact in the stiffened panel lingers for periods exceeding $3 \mathrm{msec}$.

The low-speed impact damaged specimen was tested in compression until failure. In the presence of damage at multiple locations the panel failed at an 


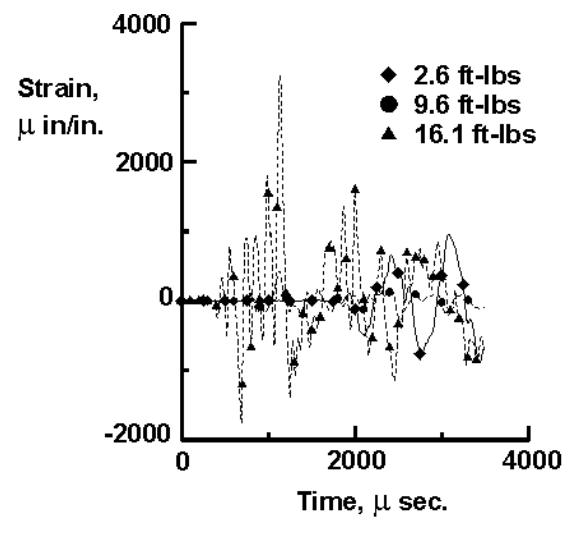

a. Strain at gage 9 .

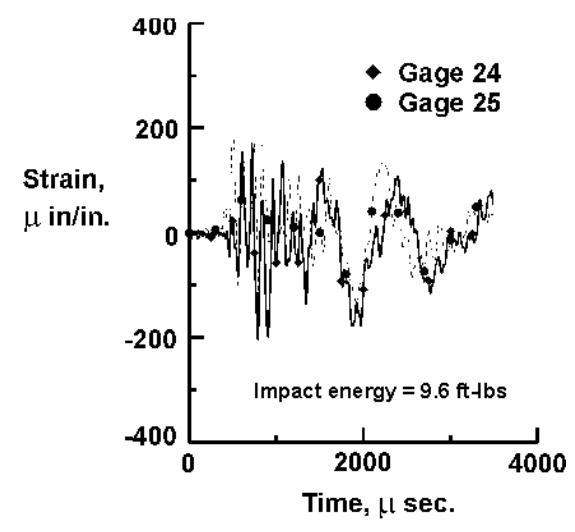

b. Strain in stiffeners

Figure 23. Typical strain response of test panel during an airgun impact event.

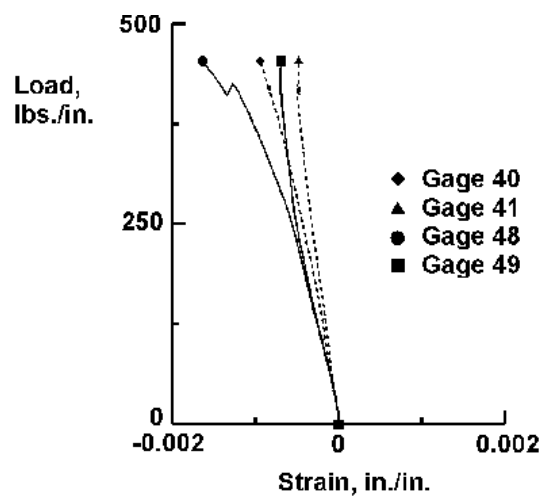

a. Strains in vertical stiffener elements

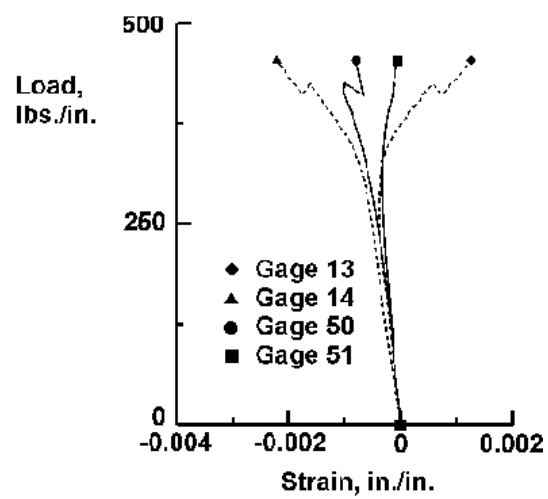

b. Strains in skin elements

Figure 24. Typical strain data for impact panel damaged panel loaded in compression.

applied loading of $453.6 \mathrm{lbs} / \mathrm{in}$. which is approximately 59 percent of the failure load for the undamaged panel. Load-strain results for selected strain gages are presented in Figure 24. Strains in two vertical stiffeners are shown in Figure 24a which suggest stiffener buckling at approximately $250 \mathrm{lbs} / \mathrm{in}$. of load. Results from back-to-back strain gages in two different skin bays are shown in Figure 24b, which indicate skin local buckling between 250 to $320 \mathrm{lbs} / \mathrm{in}$. of applied load. These results suggest compared to the undamaged compression panel where local buckling occurs at approximately $300 \mu$ in./in., the buckling of the skin and stiffener elements for the impact damaged panel occur at approximately $500 \mu \mathrm{in}$./in.

In summary, the failure modes in the full-size compression panel specimen are consistent with those observed from the element tests. The estimates for panel buckling modes and loads using existing analysis methods and finite element analyses compare well with the experimental results, considering that local skin and stiffener buckling occurred prior to failure. The panel carried a maximum load of approximately $775 \mathrm{lbs} / \mathrm{in}$. without impact damage and a load of $454 \mathrm{lbs} / \mathrm{in}$. with induced damage at three locations which suggests the impact damage tolerance of the isogrid design. To prevent skin-stiffener separation as the dominant failure mode, local buckling needs to be prevented.

\section{Combined Compression and Shear Load}

Based on the results from the previous tests, the isogrid panel for combined compression and shear loads was designed. The panel design was for combined loading conditions shown in Table 1 together with a strength constraint at $3,000 \mu \mathrm{in}$./in. The panel dimensions are presented in Figure 3.

The combined loading test fixture used in this study evolved from a shear test fixture (Reference 9) 
where the load is applied along the edge of the fixture and not at the corner pins as with a usual 'picture frame' shear test fixture (see schematic of fixture in Figure 25a). The combined loading test fixture used here is a modification to this shear test fixture where, as illustrated in Figure 25b, the shear test fixture is rotated by $90^{\circ}$ and the compression load is applied using a standard test machine. The shear load identified as ' $\mathrm{S}$ ' in Figure 25b is applied by a load mechanism that involves a hydraulic actuator, a load cell, and a reaction frame. The rollers between the test machine bottom

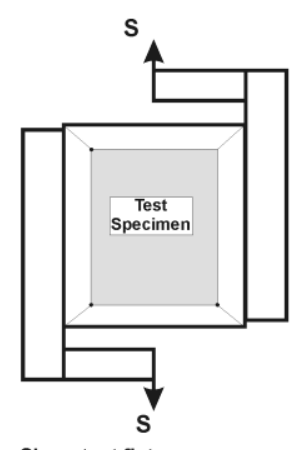

a. Shear test fixture

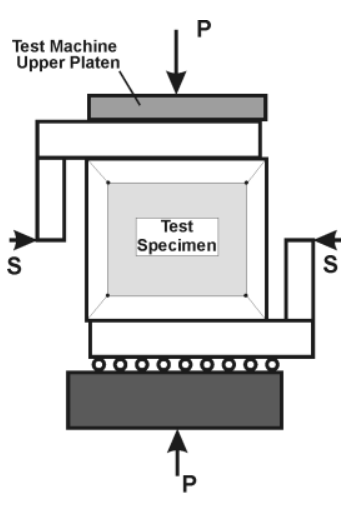

b. Combined-loads test fixture
Figure 25. Schematic of combined load test fixture.

platen and the test fixture allow shear load application while the panel is under a compression load. The shear load ' $\mathrm{S}$ ' can be controlled independent of the compression load or can be a percentage of the compression load. A photograph of the combined load fixture with a test panel located in the test machine is shown in Figure 26.

A photograph of the combined loads isogrid panel specimen and a schematic of the instrumentation pattern are shown in Figure 27. This panel has a 24inch-wide by 28 -inch-long test area. The test specimen was instrumented with 69 strain gages to monitor specimen strains and 14 LVDT's were used to measure displacements. As noted in the analysis section of this paper the combined loading test panel was tested for three loading conditions. Since the panel was not expected to buckle, only linear analysis was conducted to predict the panel response.

Condition A - Compression load. The isogrid panel was loaded to $417 \mathrm{lbs} / \mathrm{in}$. in compression, with no failures. The results for out-of-plane displacements at selected skin and stiffener intersections or node locations are shown in Figure 28. The experimental results for both locations identified by solid lines in this figure suggest near linear response.

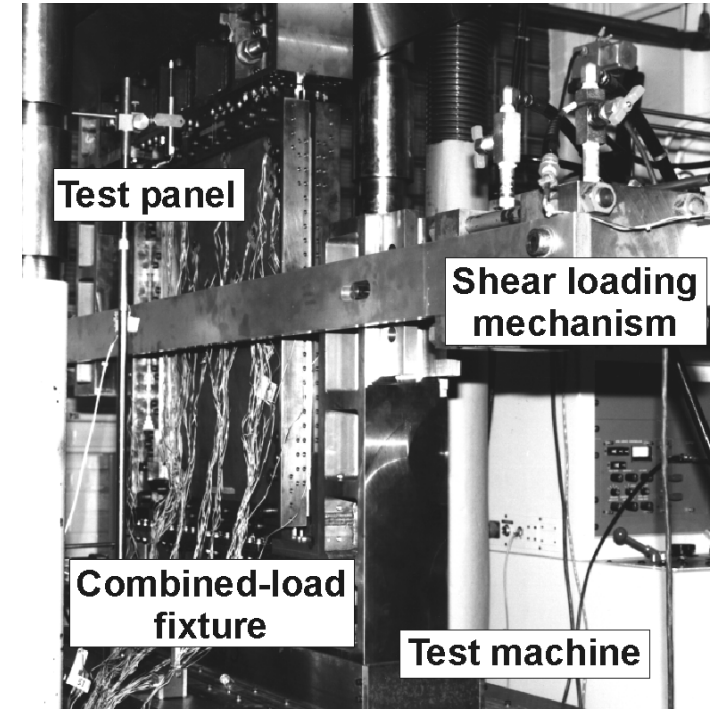

Figure 26. Photograph of combined load test fixture and test specimen in a test machine.

No local or global buckling is indicated up to the intended loading condition. The linear analysis results presented in this figure over predicts out-of-plane displacements. Strain results at two selected locations are shown in Figure 29. Strain results from back-toback gages on a vertical stiffener are shown in Figure 29a. A comparison with experimental strain results suggests that the analysis over predicts stiffener strain. The over prediction of out-of-plane displacements and stiffener strain results presented in Figure 28 and 29a could be due to an inaccurate analytical representation of stiffnesses in the load introduction regions along the test panel edges. Strain results from the back-to-back rosettes on a central triangular skin element are presented in Figure 29b. Strain gages 25 and 28 are in the direction of loading while gages 26 and 29 are the transverse gages. There is very good correlation between the analytical and experimental strains for this location. This could be due to proper load diffusion into the region that is away from the test panel boundaries. The analytical results from this region are considered to be representative of the test panel response. Based on the panel response, it appears that the analysis method used for design captures the buckling response in compression adequately.

Condition B - Shear load. For this loading condition the isogrid panel was loaded in shear to 243 lbs/in. The corresponding out-of-plane displacements are shown in Figure 30. The out-of-plane displacement results for four triangular skin elements are shown in Figure 30a. There is reasonable comparison between the test and the linear analysis results for regions that do not exhibit nonlinear deformation. The results in 


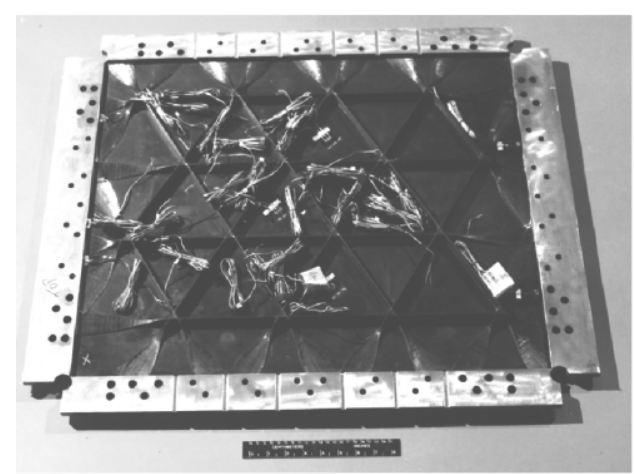

a. Combined load isogrid test panel

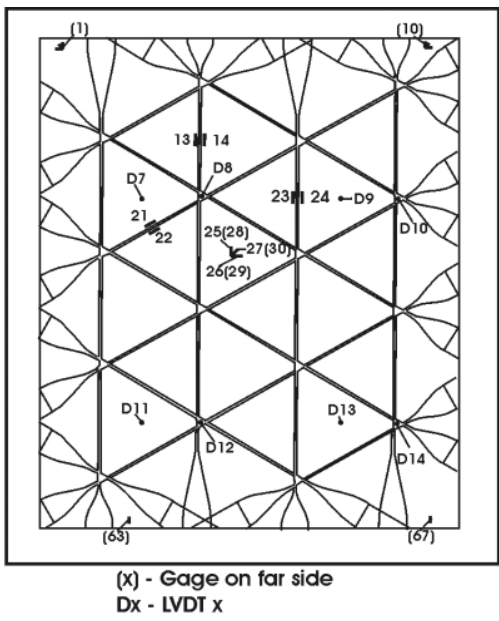

b. Instrumentation locations on the combined load isogrid test panel

Figure 27. Combined load isogrid test panel and instrumentation locations.

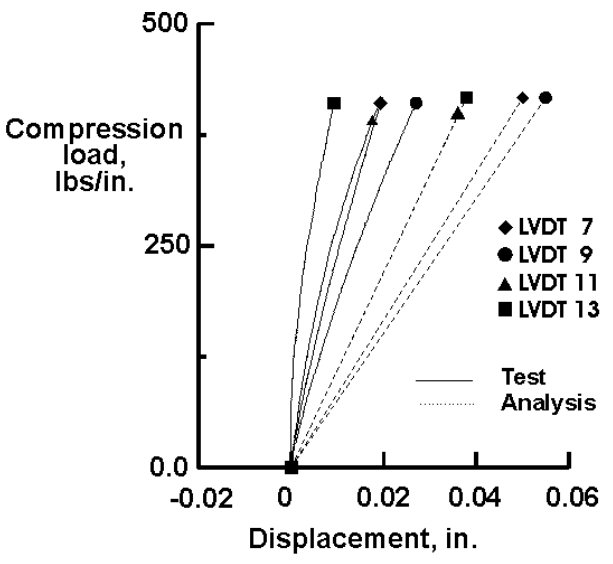

a. Skin out-of-plane displacement

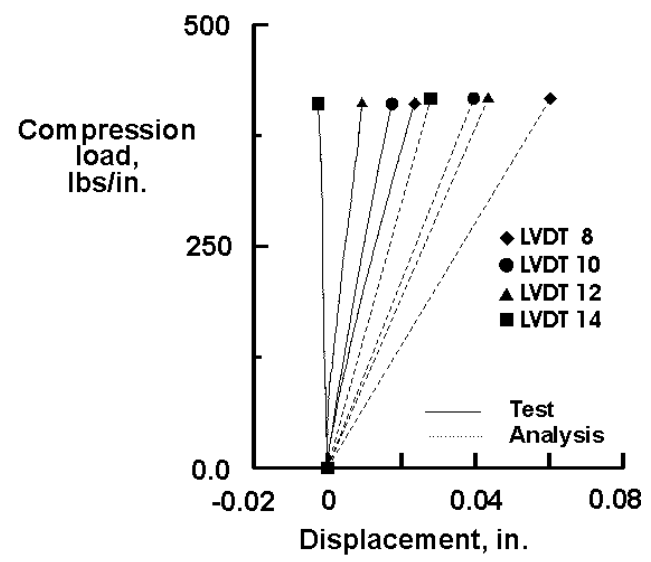

b. Node out-of-plane displacement

Figure 28. Out-of-plane displacements for compression loaded combined loads panel.

Figure 30 suggest that skin elements at LVDT locations 9 and 11 exhibit nonlinear behavior. The displacement results at the node locations (Figure 30b) from the test suggest that the panel was bending about the corner where LVDT 14 was located. A close examination of the strain results for the skin element presented in Figure 31a exhibit nonlinear response beyond a loading of approximately $100 \mathrm{lbs} / \mathrm{in}$. suggesting local buckling of this skin element. The strain results shown in Figure $31 \mathrm{~b}$ from the back-to-back strain gages located on a stiffener in the close vicinity of this skin element show predominantly linear response. The above results indicate that the skin panels buckled locally at approximately $150 \mathrm{lbs} / \mathrm{in}$. This result indicates that the analysis method used for design over predicted skin buckling load by approximately $200 \mathrm{lbs} / \mathrm{in}$. At the beginning of panel unloading, a delamination occurred in the corner where strain gage 1 (Figure 27b) was located. This axial gage indicated a strain of approximately $0.003 \mathrm{in} . / \mathrm{in}$. corresponding to this load. This is the location where the finite element analysis predicted buckling to occur. After unloading, this region was inspected by a NDE method and it was confirmed that a small delamination has occurred and its size and location was clearly defined. In an attempt to stabilize the delamination, a small hole was drilled at the center of the delamination and the sublaminates were clamped together using washers and a small bolt prior to the combined load test. 

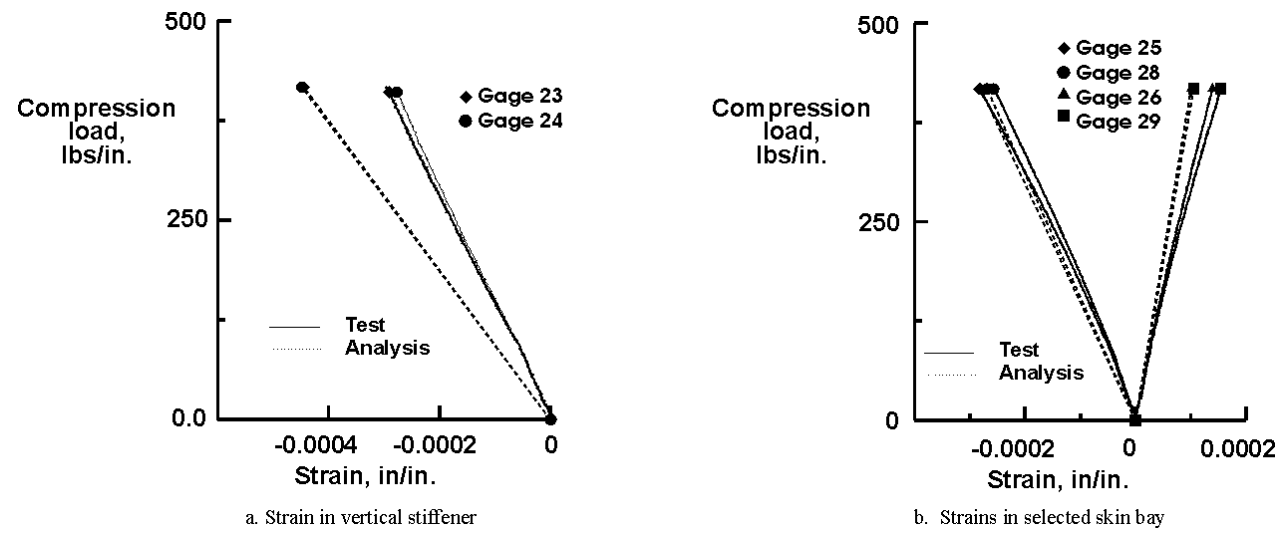

Figure 29. Comparison of analytical and experimental strain results for compression loaded combined loads test panel.
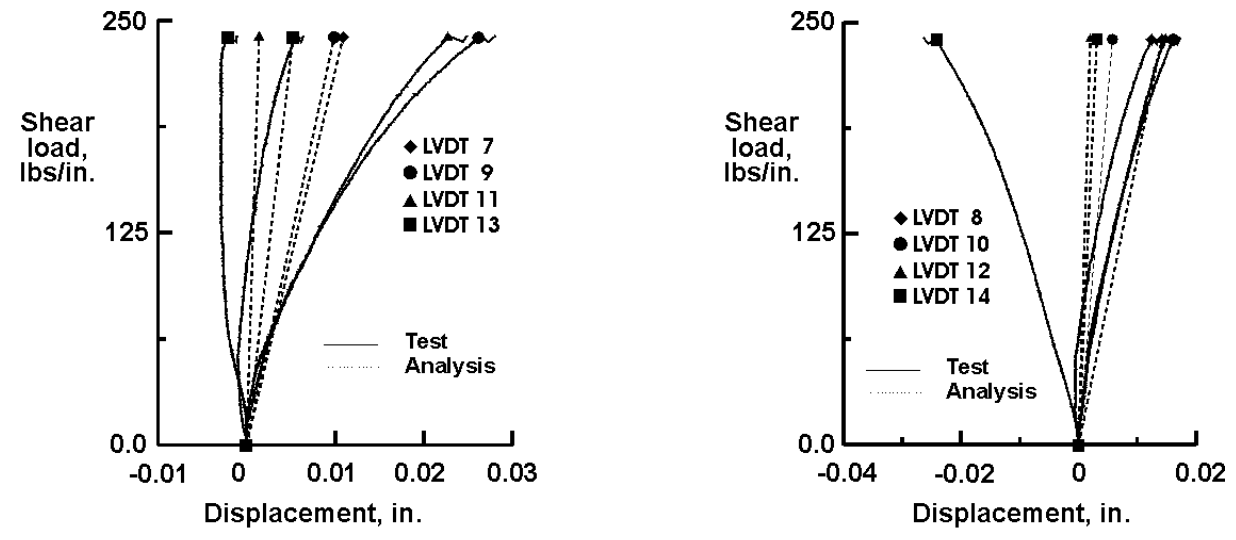

a. Skin out-of-plane displacement.

b. Node out-of-plane displacement.

Figure 30. Comparison of analysis and experimental out-of-plane results for shear loaded combined loads test panel.

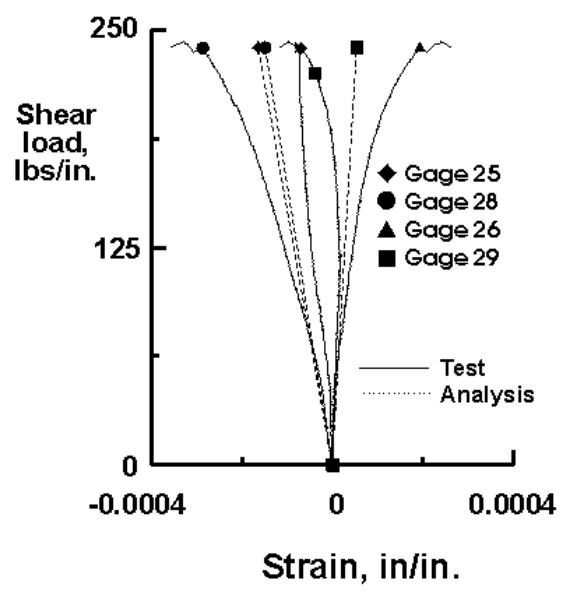

a. Strain in skin

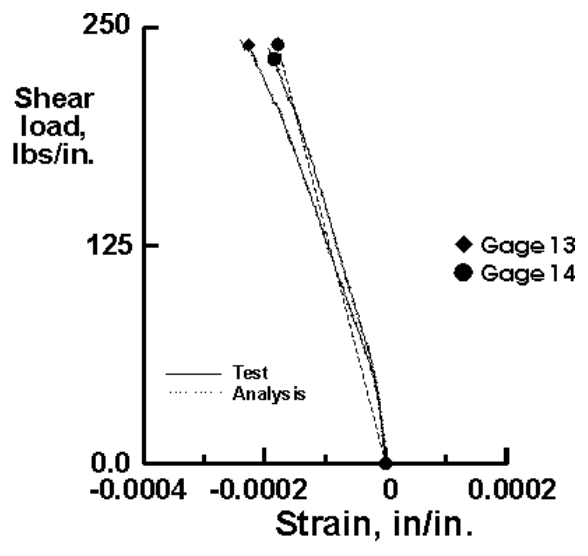

b. Strain in vertical stiffener

Figure 31. Comparison of analysis and experimental strain results for shear loaded combined load test panel. 
Condition $\boldsymbol{C}$ - Combined load For this loading condition the test specimen was loaded in a combined load of compression and shear where the shear load is 60 percent of the compression load. The specimen was loaded to failure, which occurred at $309 \mathrm{lbs} / \mathrm{in}$. in compression (the corresponding shear loading is 187 lbs/in.). Selected results from this test are shown in Figures 32 through 34 . The out-of-plane displacement results for skin elements shown in Figure $32 \mathrm{a}$ indicate that local buckling of the skins occurs at a compression loading of approximately $250 \mathrm{lbs} / \mathrm{in}$. (150 lbs/in. shear). The displacement pattern for the nodes presented in Figure $32 \mathrm{~b}$ suggest an accentuated bending about the node where LVDT 14 is located. The displacement

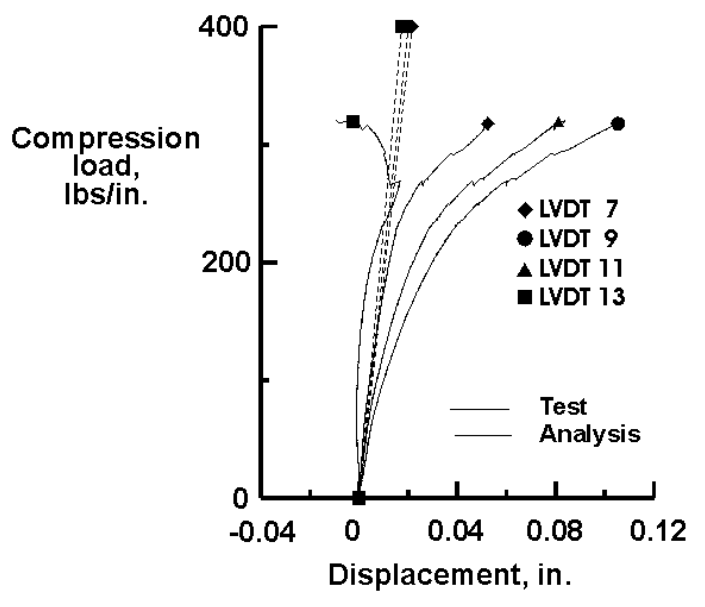

a. Skin out-of-plane dsplacement. compression loading corresponding to failure is approximately $309 \mathrm{lbs} / \mathrm{in}$., which is soon after buckling of the diagonal stiffener. The location of strain gage 1 corresponds to the region of the panel that was repaired after the shear test. Strain gages 10 and 63 register very small values through the test. The panel failed along the compression loading ends as shown in Figure 35. Nondestructive inspection of the panel indicated that the panel damage is limited to a narrow band across each end and the integrity of the rest of the panel was maintained through the test.

In summary, the test points from the three testing conditions has been plotted as pentagon symbols

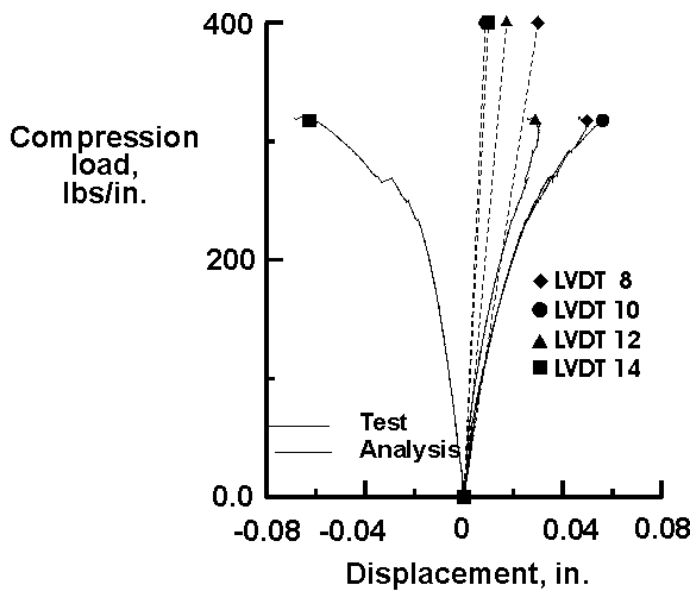

b. Node out-of-plane displacement.

Figure 32. Comparison of analytical and experimental out-of-plane displacement results for combined loaded test panel.

results from these LVDT's do not suggest global buckling. The strain results at the center skin location, a longitudinal and a diagonal stiffener location are presented in Figure 33. The strain from back-to-back strain gages indicate that this skin element also buckled at a compression loading of approximately $250 \mathrm{lbs} / \mathrm{in}$ (150 lbs/in. shear). The strain magnitudes from the linear analysis results compare well with the experimental results until the load nears the local buckling load. The strain results for the longitudinal stiffener presented in Figure $33 \mathrm{~b}$ suggest no local buckling and the analysis results for strain compare well with the experimental results. The diagonal stiffener, however, appears to buckle at a compression load of approximately $270 \mathrm{lbs} / \mathrm{in}$. as indicated by the departure in the strain data in Figure 33c. Experimental strain results from strain gages located in the opposite corners of the panel are presented in Figure 34 which suggest that panel failure initiated at strain gage location 1 and then at strain gage location 67 . The on the buckling load interaction curve as shown in Figure 36. The compression load (Condition A) did not result in skin or stiffener buckling, therefore the exact location of the pentagon symbol is not defined which is symbolized by the up arrow. The shear load (Condition $B$ ) resulted in skin buckling at approximately 150 lbs/in. as shown in the figure. The combined load (Condition $C$ ) resulted in buckling in the skin and stiffeners at $250-270 \mathrm{lbs} / \mathrm{in}$. This resulted in obtaining only $77 \%$ of the required load to be buckle resistant to the interaction curve. The final failure load is also shown in Figure 36 and it falls just outside of the interaction curve. The failure might have been initiated from the preexisting delamination in one corner of the panel from the shear load. A reasonable agreement was obtained between the experimental and computed results whenever buckling of the elements did not occur. The methodology of applying a combined compression and shear load to a panel has been verified with the testing of an isogrid panel. 


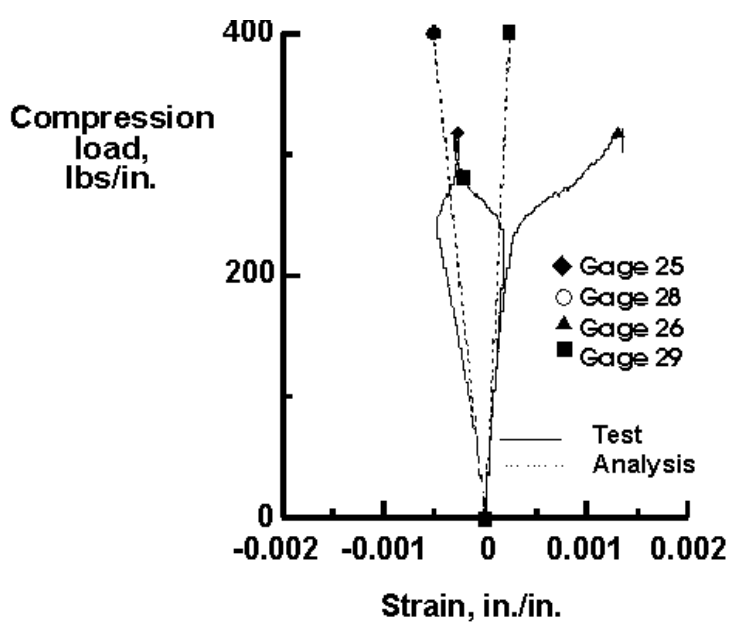

a. Strains in skin

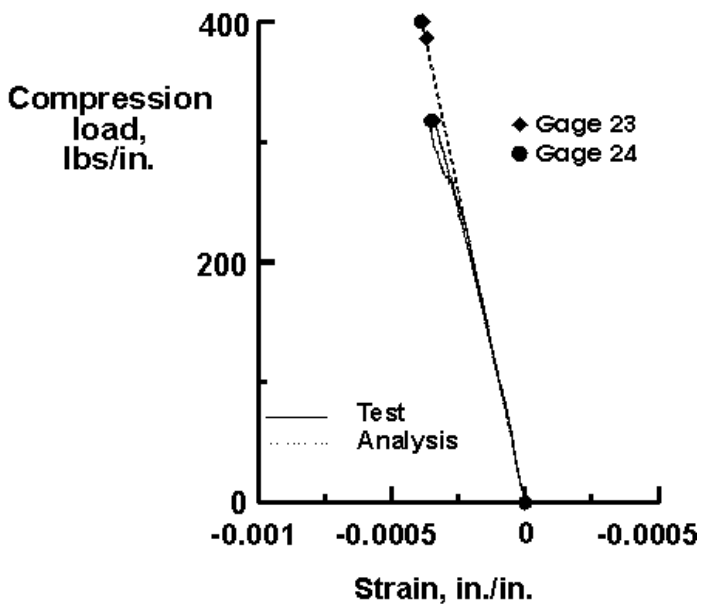

b. Strains in vertical stiffener

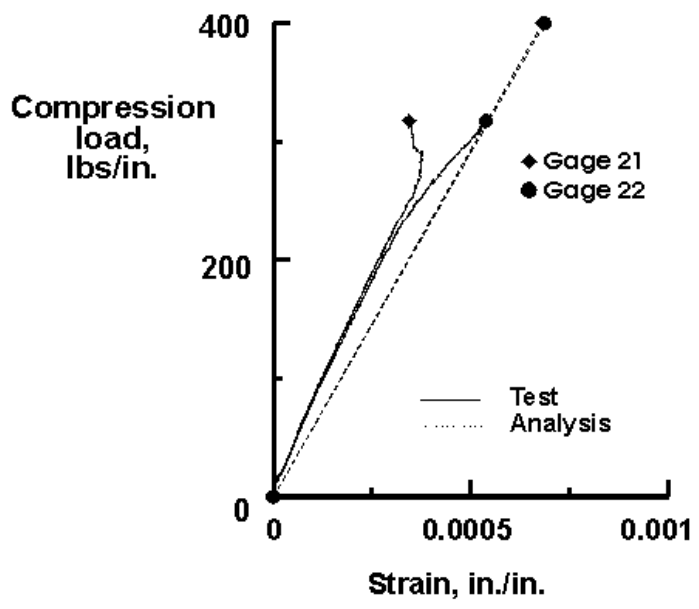

c. Strains in diagonal stiffener

Figure 33. Comparison of analysis and experimental strain results for combined load test panel.

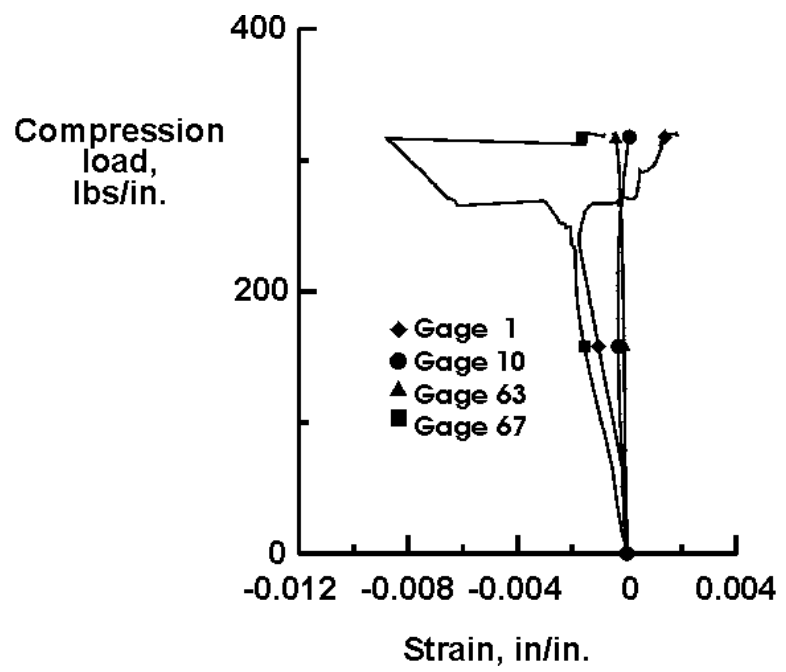

Figure 34. Strain gages at corners of specimen.

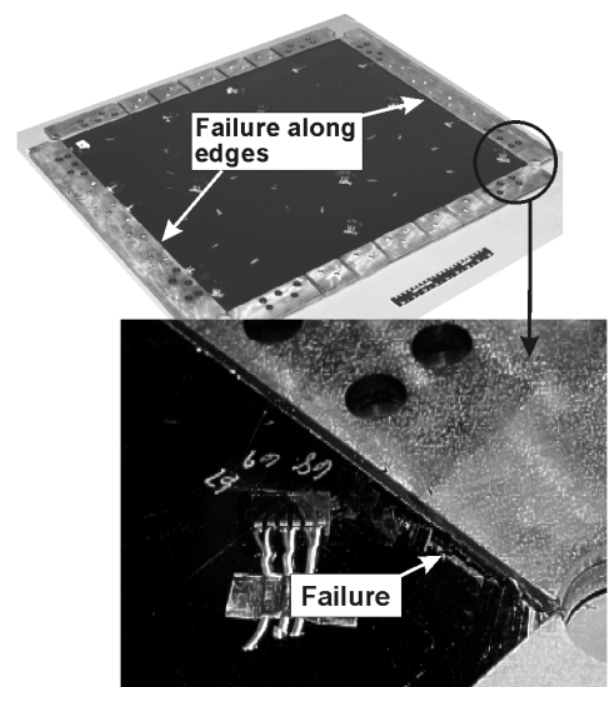

Figure 35. Failed isogrid panel.

\section{Concluding Remarks}

A design and manufacturing approach for developing an isogrid structural concept for application to a rotorcraft fuselage has been presented. Specifically, the use of genetic algorithms in the design optimization led to a design that was weight competitive with the competing sandwich designs. Through the element tests the concept of tapering the grid height at the panel edge while increasing its footprint was demonstrated to be an effective method to introduce loads into the isogrid panel and eliminate additional parts necessary for attaching to the 


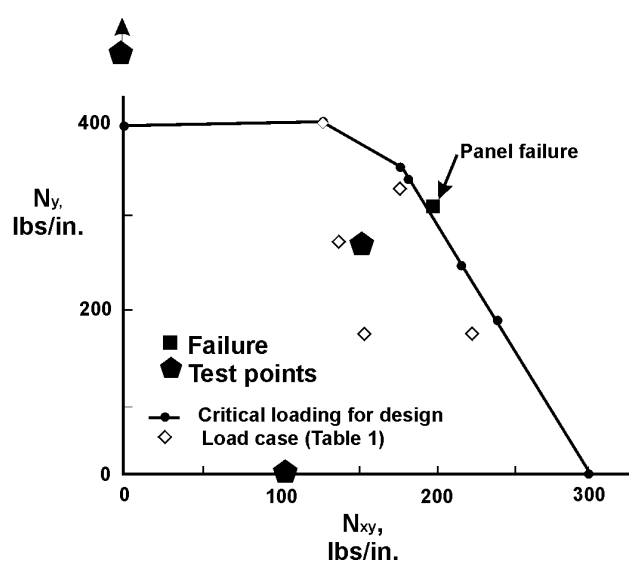

Figure 36. Design load interaction curve with test points.

surrounding structure. The panel compression tests with barely visible low-speed impact damage at three distinctly different locations demonstrated the damage tolerance of the grid-stiffened panel. The impactdamaged panel subjected to compression loading failed away from the impact site and along the panel edge region. Buckling load predictions for the compression loaded panel obtained by using smeared analysis method that accounts for both the local as well as global buckling and finite element analysis compare within 12 percent of the experimental results. This constituted validation of the design methods for grid-stiffened panels.

The combined load panel design was generated using the design tool based on smeared theory and was manufactured using an automated fiber placement technique. The panel did not buckle when tested to $417 \mathrm{lbs} / \mathrm{in}$. compression loading and exhibited close to linear response. The linear analysis results captured the compression response of this panel accurately. When subjected to a shear loading only condition only, local buckling of the skin elements was indicated at $150 \mathrm{lbs} / \mathrm{in}$. When combined compression and shear loading was applied to the isogrid panel, skin and stiffener buckling occurred at $250-270 \mathrm{lbs} / \mathrm{in}$. or approximately 77 percent of the desired load before buckling should occur. The methodology of applying a combined compression and shear load to a panel has been verified with the testing of an isogrid panel. The combined loads test fixture can be used for testing other specimens in combined loading.

A low cost single fiber placement head, in contrast to the expensive traditional multi-tow fiber placement head, can be used to fabricate the grid structure. Automation scale up can easily be achieved by associating one head with each stiffener. The fiber placement heads for one of the primary directions can be linked together to create a single pass in the $0 / 60$ / or -60 direction and to coordinate the steering that creates the edge transition. Material build up due to intersecting continuous fiber ribs can be manipulated to yield a constant grid height throughout the panel.

\section{References}

1. Isogrid Design Handbook, NASA CR-124075, Rev A, February 1973.

2. Vanderplaats, B.N., "Structural Optimization by Methods of Feasible Directions," Computers and Structures, Vol. 3, 1973, pp. 739-755.

3. Jaunky, N., Knight, N.F., Ambur, D.R., "Optimal design of grid-stiffened composite panels using global and local buckling analysis," AIAA Journal of Aircraft, 1998, 35 (3),478-86.

4. Jaunky, N., Knight, N.F., Ambur, D.R., "Buckling of arbitrary quadrilateral anisotropic plates," AIAA Journal, 1995, 3, 938-44.

5. Jaunky, N., Knight, N.F., Ambur, D.R., "Buckling analysis of general triangular anisotropic plates using polynomials," AIAA Journal, 1995, 33, 2414-7.

6. Rankin. C. C., Brogan, F. A., Loden, W. A. and Cabiness, H. D., "STAGS Users Manual, Version 3.0," Lockheed Martin Missiles \& Space Co., Inc., Advanced Technology Center, Report LMSC P032594, 1999.

7. Riks, E., "Progress in Collapse Analysis," Journal of Pressure Vessel Technology, Vol. 109, 1987, pp. 27-41.

8. Park, K., C., "An Improved Stiffy Stable Method for Direct Integration of Nonlinear Structural Dynamics," Journal of Applied Mechanics, Vol. 42, June 1975, pp.464-470.

9 Farley, G., L. and Baker, D., J., "In-plane Shear Test of Thin Panels," Experimental Mechanics, Vol. 23, No 1,81-88, March 1983. 